"COMPLEXOS DO DIPEPTIDEO GLICILTRIPTOFANO COM ION $\mathrm{Cu}^{2+}$ : CARACTERIZAÇĀO POR MEDIDAS DE ABSORÇÃO ELETRONICA NO VISIVEL E POR RES SONÂNCIA PARAMEGNETICA ELETRONICA. Otaciro Rangel Nascimento

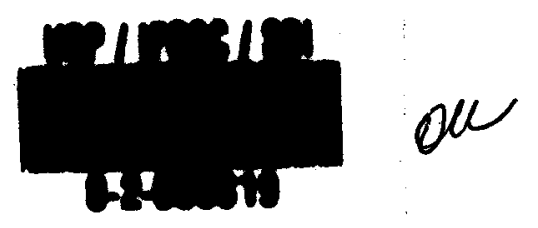

Tese apresentada ao Ins tituto de Fîsica e Quîmica de são Carlos, Universidade de são Paulo, para obtenção do título de Livre-Docente. 
Não poderia deixar de expressar o meu agradecimento a todas as pessoas que contribuiram para a realização deste tra balho.

Gostaria, portanto, de agradecer ao Prof. Sergio Mascarenhas pelo estímulo e apoio que venho recebendo desde o meu primeiro dia de trabalho aqui neste departamento.

Ao Prof. Horácio Panepucci pela franquia de seu laboratório e seu apoio pessoal.

Ao Prof. Marcel Tabak com o qual tenho dividido to dos os trabalhos e discussões realizados no grupo de biofísica.

Aos Profs. E.Castellano, Yvonne Mascarenhas, Glaucius Oliva e ao Julio Zukerman, do grupo de cristalografia, que têm apoiado toda interação entre os dois grupos.

Ao Prof. Jan Slaets, Valdeci Massaro, Valdir de Camar go Melchior, pelo apoio no uso do centro de computação e ao estudante Marcos Pizarro, pelo uso do digitalizador de gráficos.

A todo o pessoal da oficina mecânica pelo apoio e pron to atendimento na infra-estrutura mecânica do laboratório de bio física.

Aos técnicos Salvador Sanches e Derminda Isabel de Moraes pela ajuala têenica no laboratório.

A todo o pessoal da administração pelo apoio constante, em especial à Maria Lucia e Lourdes Basseto pelos trabalhos de dat1lografia e revisão do português.

Aosestudantes Oswaldo Baffa, Ignez Caracelli, Marcio colombo e Jorge Honel, pela ajuda, estímulo e participação em todas as atividades do laboratório.

Em especial à minha companheira de vida, Cleusa, pelo apoio incansāvel às minhas iniciativas, trabalhos e idiosincra- 
sias.

Meu agradecimento à "Natureza" por estar me mantendo saudável, condição essencial para realização de qualquer tra balho. 
RESUMO

Este trabalho apresenta os complexos formados pelo ion de $\mathrm{Cu}^{2+}$ com o ligante Glicil-Triptofano.

As caracterizações dos complexos, que são formados em diferentes pHs, são feitas utilizando - se a técnica de absorção eletrônica no visível (350 a $1100 \mathrm{~nm}$ ), e a técnica de Ressonān cia Paramagnética Eletrōnica em duas temperaturas: ambiente e ni trogênio Iİquido, com as amostras em solução aquosa na razão de 10 ligantes para 1 metal.

Três complexos são evidenciados nas seguinte faixas de pHs: $4.0-6.0 ; 6.5-11.0$ e acima de 12.0. Os complexos são propostos serem $\mathrm{CuL}_{2}, \mathrm{CuL}\left(\mathrm{H}_{2} \mathrm{O}\right)$ e $\mathrm{CuL}(\mathrm{OH})\left(\mathrm{H}_{2} \mathrm{O}\right)$, respectivamente, com base nos dados espectroscópicos e pKs dos grupos desprotonáveis do dipeptídeo ligante.

O complexo tridentado $\mathrm{CuL}\left(\mathrm{H}_{2} \mathrm{O}\right)$ foi cristalizado e me didas de RPE no monocristal permitiram obter o tensor giromagnético molecular. Interação dipolar entre ions vizinhos, não permi te a determinação do tensor hiperfino do complexo.

o complexo a pH acima de 12.0, mostrou o efeito do re sỉduo lateral pesado do Triptofano na estereoquímica ou simetria do complexo, distorcendo a simetria quadrado planar na direção da simetria tetraédrica, e diminuindo a constante hiperfina $A_{2}$ para os valores compativeis com aqueles existentes nas proteinas azuis além de mostrar a quebra da simetria axial medidas por $g_{x}-g_{y}$. 
Distinct species of the Glycil-Triptophan with $\mathrm{Cu}^{2+}$ is presented in this work.

The spectroscopic caracterization of these complexes formed in different $\mathrm{pH}$ was made using visible light absortion ( 350-1100 nm) and electron paramagnetic resonance at room and liquid nitrogen temperatures, with the samples in aqueous solution at the rate of $10 \mathrm{~L}: 1 \mathrm{M}$ (10 ligand to 1 metal).

Three species were identified in the range of $\mathrm{pH}$ be tween $4.0-6.0 ; 6.5-11.0$ and above 12.00 respectively. The spectroscopic data and $\mathrm{pK}$ values of the Gly-Trp deprotonatable groups (in the presence of the metal) suggest the following complexes $\mathrm{CuL}_{2}(\mathrm{pH}-5.0), \operatorname{CuL}\left(\mathrm{H}_{2} \mathrm{O}\right)(\mathrm{pH}-9.00)$ and $\mathrm{CuL}(\mathrm{OH})\left(\mathrm{H}_{2} \mathrm{O}\right)$. The tridentate complex $\mathrm{CuL}\left(\mathrm{H}_{2} \mathrm{O}\right)$ was crystalized and paramegnetic measurements using single crystals permited to obtain the molecular giromagnetic tensor, but dipole-dipole interaction between neighbor ions masked the hiperfine interaction. The complex above $\mathrm{pH}=12.00$ showed the bulky effect of the triptophan side - chain in the stereochemistry, or symmetry of the complex. The square planar symmetry is destroyed and a distorted tetrahedral. symmetry is. achieved and the hiperfine parameter $A_{z}$ is disminished toward value that occurs in blue proteins and axial symmetry is broken viewed by $g_{x}-g_{y}$. 


\section{INTRODUÇÃO}

1.1 COORDENAÇÃO METALICA EM PEPTIDEOS E PROTEINAS

E interessante relacionar aqui o papel de grupos molecu lares existentes em proteínas que são quimicamente ativos, na com plexação de ions metálicos, especialmente os do grupo do ferro.

Os diversos residuos, ou cadeias laterais, dos amino-àcidos que compõem as proteínas, são geralmente ativos mas, especi almente alguns grupos, são mais ativos e serão aqui salientados.

Entre os residuos de amino-ácidos mais ativos estão os nitrogènios do anel imidazol da Histidina e, por ser tão ativo, tèm recebido consideração especial em estudos bioquímicos e em complexos de coordenação metálica (Sundberg and Martin, 1974). Em proteinas, para as quais as vizinhanças dos àtomos metálicos es tão determinados por difração de raios $x$ e sequenciamento químico, hā muitos casos onde uma ou mais histidinas aparecem como ligan tes. O nitrogênio envolvido perde seu proton com o crescimento do pH e, então, fica livre para ligar o metal. Nitrogênios de grupos amino são tambēm ótimos ligantes para ions metálicos, embora estes nitrogênios sejam eletronicamente diferentes de nitrogênios de anéis imidazóis. Existe pelo menos um grupo amino-terminal en pro teỉnas e, em $\mathrm{pH}$ alcalino este nitrogênio perde um proton e pode, então, complexar com o ion metálico. Além disso, é comum existir resíduos aminados de amino-ácidos, presentes em uma sequencia pro teica, que também pode participar como ligante. Um exemplo é o nitrogēnio $\varepsilon$, do grupo amina da lisina. A participação deste grupo, geralmente ocorre em pH bem alcalino. Grupos carboxilicos, quando ionizados, possuem oxigênics negativamente carregados, e po dem participar de coordenação metálica. Estes oxigênios estão pre sentes no terminal C (carboxila), de uma proteína, bem como em resíduos laterais de amino-ácidos dicarboxỉlicos, tais como resí- 
duos do ācido aspārtico e glutāmico. A tirosina pode participar de ligações metālicas, através do grupo fenólico, em pH alcalino, en quanto que a cisteina participa com o grupo sulfidrilico, com o proton dissociado em pH conveniente, fazendo com que o enxofre, negativamente carregado, participe da ligação metálica. A partici pação do grupo sulfidrilico tem sido apresentada por alguns autores como o grupo importante na explicação de complexos de $\mathrm{Cu}^{2+}$, nas chamadas proteínas azuis.

A tabela I, abaixo, dá uma idéia dos diferentes grupos existentes em proteinas, com os seus pKs de dissociação protinnica

\section{GRUPO IONIZÃVEL RESIDUO DE AMINO-ACIDO PK INTRINSECO}

$\begin{array}{llc}\alpha-\mathrm{COOH} & \text { Terminal carboxílico } & 3.5-4.0 \\ \beta, \gamma-\mathrm{COOH} & \text { Aspärtico, glutāmico } & 4.0-5.0 \\ \mathrm{~N}-\text { imidazol } & \text { Histidina } & 6.0-7.0 \\ \alpha-\mathrm{NH}_{3}^{+} & \text {Terminal amina } & 7.5-8.0 \\ \text { Sulfidril } & \text { Cisteina } & 10.0 \\ \xi-\mathrm{NH}_{3}^{+} & \text {Lisina } & 10.0 \\ \text { Fenölico } & \text { Tirosina } & 9.5-10.5 \\ \text { Guanidina } & \text { Arginina } & 12.0\end{array}$

TABELA - I

Grupos ionizáveis de proteinas que participam em ligações metálicas.

E importante salientar aqui que os nitrogênios, do grupo amida da cadeia peptídica, são também ativos na ligação metá lica.

Para todos os ligantes ionizāveis o pH, no qual a for mação do complexo metálico ocorre, geralmente é bem menor do que 
os valores de pK intrínseco de cada grupo. A ionização e complexação depende, básicamente, da estabilidade do conjunto inteiro das ligações envolvidas. Uma revisão ampla sobre complexos metálicos de amino-ácidos e peptídeos, salientando a ordem de pH nas ligações e outros fatores (estereoquímicos), com inúmeros exem plos, é apresentado por Hans C. Freeman em "Inorganic Biochemist ry", 1973, cap. 4 .

Os pHs nos quais os protons e metais competem com i gual sucesso, na ligação com os nitrogênios do dipeptídeo glicil glicina, è apresentado na Tabela II. Note-se que o grupo amida dissocia o proton em favor dos metais fazendo-o, mais facilmente, para o ion de $\mathrm{Cu}^{2+}$.

ION METÁLICO

PK DO GRUPO

$+\mathrm{H}_{3} \mathrm{~N}-\mathrm{CH}_{2}-\mathrm{CO}-\mathrm{NH}-\mathrm{CH}_{2}-\mathrm{COO}^{-}$

$\begin{array}{llc}{ }^{-} & 8.1 & 213 \\ \mathrm{Co}^{2+} & 7 & 10 \\ \mathrm{Ni}^{2+} & 6.5 & 9.7 \\ \mathrm{Cu}^{2+} & 4.2 & 4.8\end{array}$

TABELA - II

Pontos médios de pH para desprotonização de glicilglicina na pre sença de metais

Complexos de peptídeos de $\mathrm{Cu}^{2+}$ e $\mathrm{Ni}^{2+}$ têem sido, particularmente, objeto de estudos exaustivos com uso de diver sas técnicas, porque eles são, ao mesmo tempo, relativamente estáveis sob o ponto de vista termodinâmico e são cinéticamente muito lábeis. Sistemas formados por peptídeos $\mathrm{Cu}^{2+}$ e $\mathrm{Ni}^{2+}$ alcançam equilibrio rápidamente e, titulação potenciométrica e medidas calorimétricas podem ser feitas sem maiores dificuladades; 
e parâmetros termodinâmicos obtidos. As cinēticas de reaçõc: são geralmente seguidas por métodos de relaxação e "stopped-flow".

Os resultados de um estudo potenciométrico é mostrado na figura 1. Na figura está representada a titulação poten clométrica de um tetrapeptídeo, na ausēncia e presença de uma con centração equimolar do ion $\mathrm{Cu}^{2+}$ (Hartzell and Gurd, 1969) . O peptideo está em sua forma zwiteriônica em $\mathrm{pH}=6$, e somente um equi valente de $\mathrm{OH}^{-}$é necessário para ionizar o proton do terminal ... $\mathrm{NH}_{3}^{+}$entre os $\mathrm{pHs} 7$ e 9. Na presença do ion de $\mathrm{Cu}^{2+}$ o proton do $\mathrm{NH}_{3}^{+}$é dissociado em um $\mathrm{pH}$ bem mais baixo porque o ion $\mathrm{Cu}^{2+}$ com pete com $\mathrm{H}^{+}$em relação ao grupo $\mathrm{NH}_{2}$. Entre os pHs 5 e 10, mais très protons são liberados. Se denotarmos as espécies formadas pela reação $\mathrm{Cu}^{2+}$ e $\mathrm{L}^{-}$teremos, inicialmente, o complexo $\mathrm{CuL}^{+}$, e a

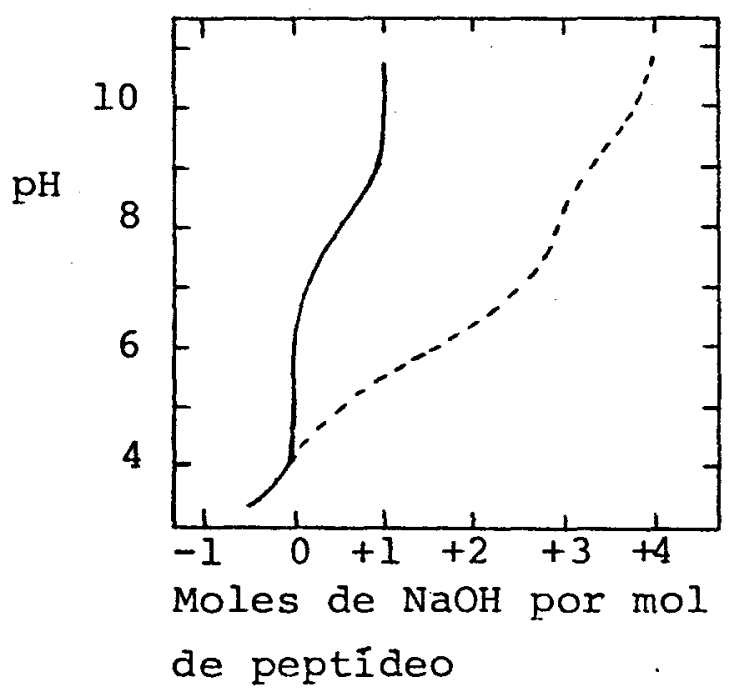

Fig. 1 - Titulação do tetrapeptídeo alanilglicilglicilglicina na ausência (curva contínua) e na presença de $1 \mathrm{Cu}^{2+}$ por peptídeo (curva pontilhada) com hidróxido de sódio (. força iōnica $=0.16, \mathrm{~T}=25^{\circ} \mathrm{C}$ ).

liberação de três protons leva à formação sucessiva dos comple xos $\mathrm{CuH}_{-1} \mathrm{~L} ; \mathrm{CuH}_{-2} \mathrm{~L}^{-}$e $\mathrm{CuH}_{-3} \mathrm{~L}^{2-}$. Entretanto, a dissociação que leva ao complexo $\mathrm{CuH}_{-1} \mathrm{~L}$, não ocorre se o segundo amino-ácido, a partir do terminal amino do peptideo, for um sarcosil ou um prolil, isto é, se o primeiro grupo peptideo não tiver um proton dis 
sociável. O mesmo ocorre com o complexo $\mathrm{CuH}_{-2} \mathrm{I}^{-}$se o tcroeixo amino-ácido for, outra vez, um dos dois acima mencionados. A des protonização então ocorre, no nitrogênio do grupo amida do peptỉdeo, e a complexação metálica ocorre com a participação do ni trogênio, sem perda da energia de ressonância da ligação peptí dica.

E interessante dar, também, alguns exemplos da coor denação metálica de algumas proteínas, para ilustrar a partici pação dos diferentes grupos e resíduos de amino-ácidos, bem co mo de outras moléculas componentes das mesmas.

Estas coordenações em proteínas têem sido estâlelecidas por diferentes técnicas tais como, métodos químicos, difra ção de raios $\mathrm{x}$ e métodos espectroscópicos em geral. Pode-se ver que uma grande parte destes ligantes são constituídos de nitrogē nios vindo de anéis imidazóis, grupos pirrólicos, nitrogênios peptídicos, etc.

A tabela III, abaixo, esquematiza diferentes protei nas, seus metais e os ligantes que aparecem, bem como o número de coordenação existentes.

\begin{tabular}{|c|c|c|c|c|c|c|c|}
\hline PROTEINA & ION METALICO & PORFIRINA & RESI DUOS & AgUA & NQ COORD. & NI TROGENIO & oxl GR:ilo \\
\hline Insulina $2 \mathrm{~N}^{2+}$ & $\mathrm{Zn}^{2+}$ ou $\mathrm{Cu}^{2+}$ & Nāo & 3 Histidinas & 3 & 6 & 3 & $=$ \\
\hline \multirow[t]{2}{*}{ Insulina $4 \mathrm{M}^{2+}$} & $22^{2+}$ & Nāo & 3 Histidinas & $3(?)$ & 6 & 3 & $3 \because$ \\
\hline & $32 n^{2+}$ & Nāo & 2 Histidinas & 2 & 4 & 2 & $:$ \\
\hline $\begin{array}{l}\text { Carboxi- } \\
\text { peptidase }\end{array}$ & $\mathrm{zn}^{2+}$ ou $\mathrm{Cu}^{2+}$ & Näo & $\begin{array}{l}2 \text { Histidinas } \\
1 \text { Glutamato }\end{array}$ & 1 & 4 & 2 & $:$ \\
\hline $\begin{array}{l}\text { Mioglobina } \\
\text { Hemog lobina }\end{array}$ & $\mathrm{Pe}^{2+}$ ou $\mathrm{Fe}^{3+}$ & $\operatorname{sim}$ & I Histidina & 0 ou 1 & 5 ou 6 & 5 & ocd \\
\hline $\begin{array}{l}\text { Miohemeritrina } \\
\text { Hemeritrina }\end{array}$ & $\mathrm{Fe}^{2+}$ ou $\mathrm{Fe}^{2+}$ & Nāo & $\begin{cases}2 & \text { Histidinas } \\
1 & \text { Tiorosina } \\
2 & \text { Aspartato } \\
1 & \text { Glutamina } \\
3 & \text { Histidinas }\end{cases}$ & 1 & $\begin{array}{l}6 \\
6\end{array}$ & $\begin{array}{l}2 \\
3\end{array}$ & $\stackrel{4}{3}$ \\
\hline Citocrano $\mathrm{C}$ & $\mathrm{Pe}^{2+}$ ou $\mathrm{Fe}^{3+}$ & $\operatorname{sim}$ & $\begin{array}{l}1 \text { Histidina } \\
1 \text { Metionina }\end{array}$ & 0 & 6 & 5 & $1, \ldots \ldots$ \\
\hline Citocramo $\mathrm{b}_{5}$ & $\mathrm{Fe}^{2+}$ ou $\mathrm{Fe}^{3+}$ & $\operatorname{sim}$ & 2 Histidinas & 0 & $\epsilon$ & 6 & c \\
\hline $\begin{array}{l}\text { Cu, an Super- } \\
\text { cxido di smutase }\end{array}$ & $\begin{array}{l}\mathrm{Cu}_{2+}^{2+\mathrm{e}} \\
\mathrm{zn}^{2+}\end{array}$ & $\begin{array}{l}\text { Nào } \\
\text { Nào }\end{array}$ & $\begin{array}{l}4 \text { Histidinas } \\
3 \text { Histićinas } \\
1 \text { Aspartato }\end{array}$ & $\begin{array}{l}0 \\
1\end{array}$ & $\begin{array}{l}4 \\
4\end{array}$ & 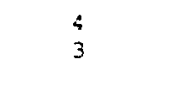 & $\vdots$ \\
\hline
\end{tabular}

Tabela III - Participação de Metais e suas coordenaçōes em algumas proteînas (Brill, 1977) 
Uma descrição mais detalhada da função e participaçāo dos metais em proteinas, è apresentada por Arthur S.Brill em : -Iransition Metals in Biochemistry" - 1977.

Neste trabalho procurou-se estudar os complexos de $\mathrm{Cu}^{2+}$ formados com o dipeptídeo Glicil-Triptofano, em função do pH na faixade 2.5 até 13.2 . O estudo é feito utilizando-se técnicas de absorção ötica visível das soluções, em diferentes pHs, e de RPE das mesmas em temperatura ambiente e nitrogênio líquido. Um dos complexos foi cristalizado e sua cristalografia foi melhor refina da, bem como o espectro de RPE, com orientação do tensor $\overline{\bar{g}}$ obti do. Uma vez que a interação hiperfina não é resolvida devido à in teração dipolar existente, não foi possivvel determinar os valores e orientação do tensor hiperfino $\overline{\overline{\mathrm{A}}}$. 


\section{CAPITULO I}

\section{PROTEINAS AZUIS}

Existe um grupo de proteinas que contem ion de $\mathrm{Cu}^{2+} \mathrm{com}$ propriedades espectroscópicas especiais chamadas "proteinas azuis", por causa da çor azul intensa que elas apresentam. Algumas destas proteinas tèm vārios ions de Cobre. A ceruloplasmina, ou ferroxi dase, tem sete ou oito, a lacase, quatro, plastocianina tem duas, e azurinas estelacianina e umecianina têm apenas um ion de cobre O peso molecular, por ion de cobre, varia entre 11.000 a 30.000 daltons. O pigmento transportador de oxigênio em inver tebrados marinhos, a hemocianina, è azul tambēm, mas não é considerada uma "proteína azul" porque a absortividade molar, por ion de cobre, é baixa em comparação com as azuis e, além disto, à valência dos ions metálicos nos cromóforos é discutida.

As verdadeiras proteinas azuis são coloridas quando o cobre é cūpricó, e clara quando cuproso.

Os estudos sobre proteínas azuis têm sido concentrados nas proteînas que contêm só um ion, desde que os resultados espectroscópicos não apresentam contribuições dos ions que não caracterizam as proteínas azuis. Isto elimina a hipótese de interação cobre-cobre na elucidação dos modelos.

Valorès experimentais de grandezas, medidas em proteí nas azuis contendo um ion, tais como parâmetros de RPE, absorção ótica e absortividade, são apresentados na tabela IV.

o comportamento experimental que mais é salientado nes tas proteĩnas, è a intensidade relativamente alta das bandas de absorção, o forte dicroismo circular associado com estas bandas; e o baixo valor da interação hiperfina de campo baixo do ion de cobre. A absortividade máxima da banda em $16 \times 10^{3} \mathrm{~cm}^{-1}(600 \mathrm{~nm})$, 
¿ duas ordens de grandeza maior que aquela apresentada por : eque nos complexos de $\mathrm{Cu}^{2+}$ (sulfatos, amino-ācidos, etc.), e uma ordem de grandeza maior que na maioria das apresentadas por pequenos peptideos. Em pH neutro, o parâmetro de interação hiperfina $\left|\mathrm{A}_{z}\right|$ para estas proteínas azuis, está entre $30 \times 10^{-4} \mathrm{~cm}^{-1}$ a $60 \times 10^{-4} \mathrm{~cm}^{-1}$ (menor que 100 gauss), enquanto que para os ions cúpricos em proteínas não azuis e em pequenos complexos, este valor varia entre $14 \times 10^{-4} \mathrm{~cm}^{-1}$ e $220 \times 10^{-4} \mathrm{~cm}^{-1}$ (maior que 140 gauss).

\begin{tabular}{|c|c|c|c|c|c|c|}
\hline Proteina & Origem & g & 9 & $\begin{array}{c}\text { A } \\
\text { (gauss) }\end{array}$ & $(\mathrm{nm})$ & $\begin{array}{c}\text { absortivi- } \\
\text { dade } \\
\left(\mathrm{mM}^{-1} \mathrm{~cm}^{-1}\right)\end{array}$ \\
\hline Azurina & $\begin{array}{l}\text { Pseudomona } \\
\text { aeruginosa }\end{array}$ & 2.052 & 2.260 & 57 & 625 & 3.50 \\
\hline $\begin{array}{l}\text { Estelacianina } \\
\text { pH } 1-9 \\
\text { pH } 10-11.5\end{array}$ & $\begin{array}{l}\text { Rhus } \\
\text { Vermicifera }\end{array}$ & $\begin{array}{l}2.025 \\
2.077 \\
2.025 \\
2.089\end{array}$ & $\begin{array}{l}2.287 \\
2.312\end{array}$ & $\begin{array}{c}33 \\
A x=55 \\
16 \\
A x=71\end{array}$ & 605 & 4.08 \\
\hline Umecianina & horseradish & 2.050 & 2.317 & 35 & 610 & 3.36 \\
\hline Locasefungal & $\begin{array}{l}\text { Poliporus } \\
\text { Versicolor }\end{array}$ & $\begin{array}{l}2.033 \\
2.051\end{array}$ & 2.190 & 88 & 610 & 4.90 \\
\hline $\begin{array}{l}\text { Superoxido } \\
\text { Dismutase }\end{array}$ & $\begin{array}{l}\text { Cêlulas } \\
\text { vermelhas } \\
\text { bovinas }\end{array}$ & $\begin{array}{l}2.029 \\
2.108\end{array}$ & 2.265 & 134 & $m$ & - \\
\hline
\end{tabular}

Tabela IV - Propriedades Magnēticas e Oticas de algumas proteínas azuis contendo um ion de $\mathrm{Cu}^{2+}$. 
Algumas proteínas azuis contêm vários ions de cujuce, sendo alguns azuis e outros não. Por exemplo, existe uma lacase de fungo que tem um sitio com $\mathrm{Cu}^{2+} \operatorname{com}\left|\mathrm{A}_{z}\right|=90 \times 10^{-4} \mathrm{~cm}^{-1}$, e um se gundo ion $\mathrm{Cu}^{2+} \operatorname{com}\left|\mathrm{A}_{\mathrm{z}}\right|=194 \times 10^{-4} \mathrm{~cm}^{-1}$, e dois outros ions de $\mathrm{co-}$ bre, que não são detectāỵeis por RPE. Na discussão de cobres de tectáveis por RPE, é conveniente classificá-los em dois grupos : Tipo 1, com $\left|A_{z}\right|<100 \times 10^{-4} \mathrm{~cm}^{-1}$ e, Tipo $2 \operatorname{com}\left|A_{z}\right|>140 \times 10^{-4} \mathrm{~cm}^{-1}$ (vănngard, 1967). O gráfico 2 mostra claramente a razão desta clas sificação. Ions de $\mathrm{Cu}^{2+}$ tipo 1 têm sido encontrados em proteînas, que apresentam a banda de absorção muito intensa (perto de $16 \times 10^{3}$ $\mathrm{cm}^{-1}$ ), isto é, nas proteínas azuis. Ions de $\mathrm{Cu}^{2+}$ tipo 2 , são en contrados em todos os outros complexos de cobre, incluindo as proteỉnas não azuis. Existem poucas excessões a esta generalizaçãa Uns poucos complexos de pequenas moléculas com $\mathrm{Cu}^{2+}$, com simetria tetraédrica com distorções, apresentam $\left|A_{z}\right|$ prōximos do limite su perior das proteínas azuis. Tem sido mostrado que, com o crescimento do $\mathrm{pH}$ em soluções de azurina, esta perde a cor (bleaching). A partir de pH 8 (Brill, 1968, Maria, 1966), o crescimento lento do $\mathrm{pH}$ faz decrescer a absorção ótica e o valor de $\left|\mathrm{A}_{z}\right|$, guardando, os dois, uma relação linear com a concentração de ions cúpri$\cos$.

Os fatores que influem sobre os parâmetros magnéticos e os de absorção ótica (absortividade e comprimento de onda), estão de algum modo relacionados (Peisach, 1967; Malmström, 1970 ; Stigbrand and Sjoholm, 1972). Tanto em estelacianina como em umecianina, mudanças na atividade ótica ocorrem concomitante com mudanças em absorção ótica e RPE. Os dados sugerem fortemente que, alterações no espectro de RPE são, necessáriamente, acompanhadas por alterações nas propriedades óticas e que, há uma relação in tima entre a estrutura que origina a absorção não usual em $16 \times 10^{3} \mathrm{~cm}^{-1}$ e o espectro do cobre Tipo 1 . 


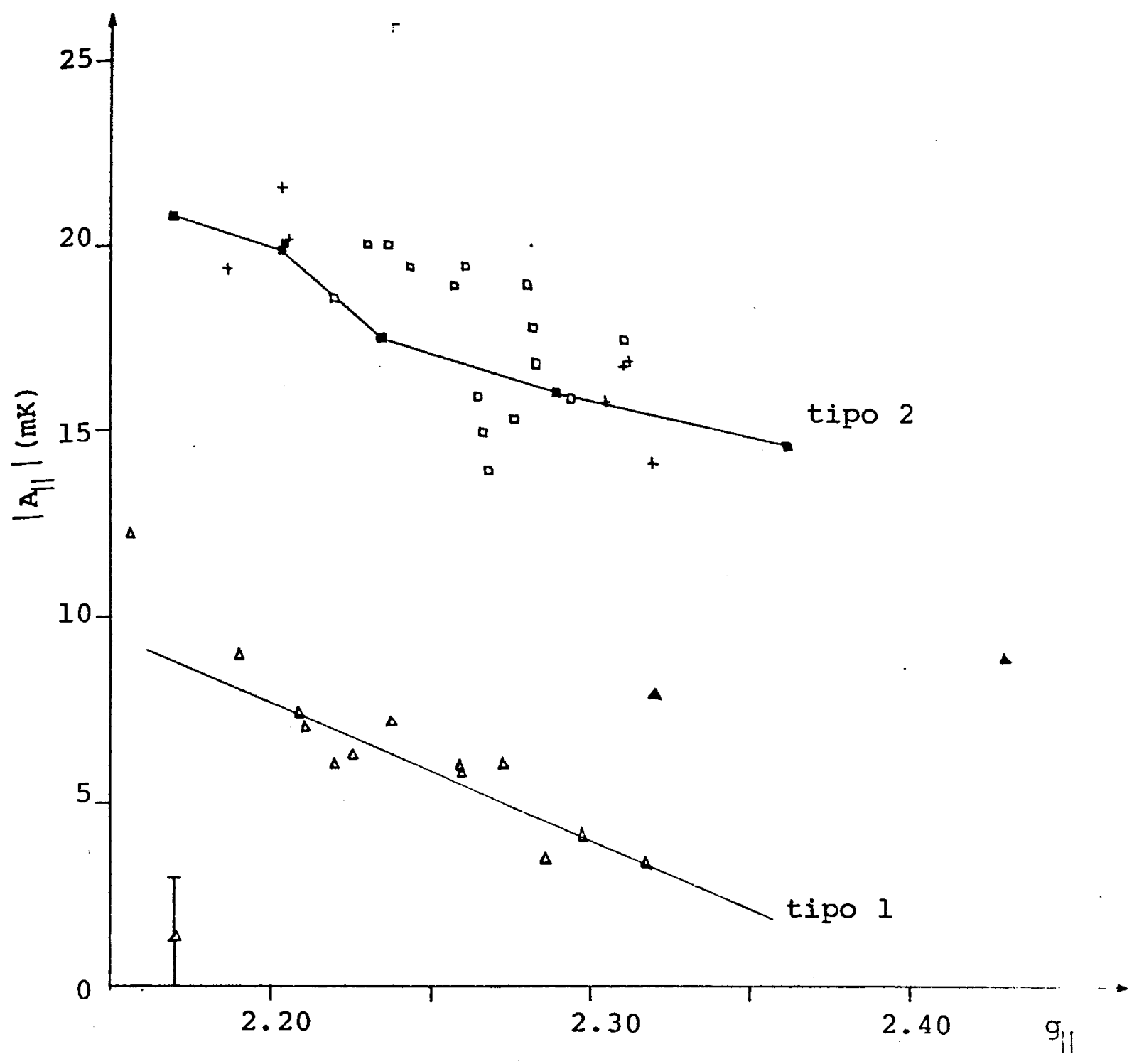

Pigura 2 - Gráfico da constante hiperfina $A_{11}$ versus $g_{\|}$moミ trando os dois tipos de complexos biológicos com - Ion de $\mathrm{Cu}(I I)$. A linha quebrada no tipo 2 Ii ga os polipeptídeos sintéticos (Vänngard, 1972) 
Não hã dados detalhados a respeito dos ligantes do ion cúprico nas proteínas azuis, embora vārios experimentos tenham si do tentados em vārias proteinas. Uma das poșî́veis coordenações po deria ser: um enxofre do residuo de cisteina (Miskowski, 1.975 ; S1Iman, 1976; Finazzi-Agro, 1973; Katoh, 1964; Graziani,1974;Mor purgo, 1974), um nitrogēnio do anel imidazol de uma histidina (. sarkley, 1975), pelo menos em algumas proteínas azuis. Em algumas proteinas azuis parece não ser fundamental existir enxofre associa do ao ion (Briving, 1975; Witwicki, 1969). E possível que o sitio do cobre nas proteinas azuis, não seja caracterizado por qualquer conjunto de ligantes, comuns atodas as proteinas da classe ( como ocorre nas hemoproteinas). A origem da cor azul intensa nestas pro teinas tem sido objeto de muitas discussões e estudos. Brill e Bryce (1968) e Brill (1977), calcularam a alta absortividade molar perto de $16 \times 10^{3} \mathrm{~cm}^{-1}(600 \mathrm{~nm})$, e também os parâmetros de RPE, fazendo um modelo não covalente de funções de ondas, misturando às funções de carāter 3d, funções $4 \mathrm{p}$ e $4 \mathrm{~s}$ do ion cobre. Estudos pos teriores feitos por Gray e Solomon (Gray,1974; Solomon,1976), mostraram que uma banda intensa em $600 \mathrm{~nm}$, poderia ser explicada por uma transição de transferencia de carga $s \sigma \rightarrow d x^{2}-y^{2}$. Estas diferentes possibilidades, deixam o problema ainda em aberto.

\section{COMPLEXOS DE COBRE COM PEQUENOS PEPTIDEOS}

o estudo com cómplexos metálicos formados por peptíces, tèm permitido muitos esclarecimentos sobre a complexação de mittais de transição, com proteínas. Atenção especial tem sido dada ao ion de $\mathrm{Cu}^{2+}$.

Um número muito grande de possibilidades de coordenação é apresentado pelos peptideos, dependendo dos resíduos de amino-ácidos participantes, bem como do pH e da relação estequiométrica. 
Sem dūvida alguma, os próprios amino-ácidos complexam com $\mathrm{Cu}^{2+}$, geralmente formando complexos $\mathrm{CuL}_{2}$, onde os nitrogénios do grupo amina e os oxigênios do grupo carboxila participam como átomos ligantes. A simetria mais comum existente nestes complexos é a quadrado planar, com pequenas distorções. Geralmente, os com plexos apresentam uma banda de absorção ótica ao redor de $16 \times 10^{3}$ $\mathrm{cm}^{-1}(600 \mathrm{~nm})$, com absortividade molar de $50 \mathrm{M}^{-1} \mathrm{~cm}^{-1}$ e espectio ce RPE com simetria axial $g_{/ /}>g_{d} e\left|A_{/ /}\right|$, da orden de 160 gauss. Cm plexos de dipeptideos com estequiometria 1:1 era pHs tais que os nitrogênios peptỉdicos tenham seus protons ionizados, são coordenados pelos nitrogènios amina e peptídico e pelo oxigênio carbo xilato sendo, o quarto ligante, uma água ou um grupo $\mathrm{OH}^{-}$. A absor tividade máxima destes complexos é cerca de $80 \mathrm{M}^{-1} \mathrm{~cm}^{-1}$. perto de $640 \mathrm{~nm}$, com espectros de RPE samelhantes àqueles apresentados por amino-ácidos.

Geralmente, linhas super-hiperfinas ce nitrogênios são mostradas no espectro de RPE.

Peptideos maiores, geralmente complexam com $\mathrm{Cu}^{2+} \mathrm{em} \mathrm{pH}$ alcalino, com a participação de dois ou três nitrogènios de gru pos peptídicos ou amidas, nitrogênio amina e lum ou zero oxigénio de carboxila ou água, com absorção em torno de $550 \mathrm{~nm}$ e absorti vidade em cerca de $150 \mathrm{M}^{-1} \mathrm{~cm}^{-1}$. Os espectros de RPE geralmente mos tram desdobramento super-hiperfino, correspondente a três ou quatro nitrogênios., e parâmetros com simetria axià lcom peguenas distorções rômbicas)

Ultimamente, um esforço maior tem siço colocado em complexos de pequenos peptídeos com ions de $\mathrm{Cu}^{2+}$, com objetivo de reproduzir os dados espectroscópicos apresentaźos pelas protểnas azuis. Aqui vale a pena citar os trabalhos de sagiura (Sugiure. 1970, 1972, 1975, 1976, 1977), onde ele e seus colaboradores c: ploram a presença do átomo de enxofre do grupo tiol, como ligante 
do ion de $\mathrm{Cu}^{2+}$. Espectros de RPE de alguns complexos de $\mathrm{Cu}^{2+}$, foram caracterizados por valores de $A$ pequenos, como aqueles en contrados nas proteinas azuis. A tabela $V$ apresenta uma relação destes resultados. Sugiura supõe simetria axial para todos os com plexos investigados e, usando a relação já conhecida para o cál culo do parâmetro de ligação, dada abaixo, obteve os valores do (I) $\alpha^{2}=A_{/ /} / \mathrm{P}+\Delta g_{/ /}+3 / 7 \Delta g_{\perp}+0.04$, $\mathrm{P}=0.04 \mathrm{~cm}^{-1}$

parāmetro de covalencia $\alpha^{2}$ (também mostrado na tabela $v$ ).

\begin{tabular}{|c|c|c|c|c|}
\hline COMPLEXOS & 9 & .9 & $\begin{array}{l}\text { A } \\
\text { (gauss) }\end{array}$ & $\alpha^{2}$ \\
\hline \multicolumn{5}{|l|}{$\mathrm{Cu}^{2+}-\alpha$-Mercaptopropionilglicina } \\
\hline Verde $\quad \mathrm{Cu}^{2+}-\mathrm{s}$ & 2.259 & 2.040 & 82 & 0.52 \\
\hline Violeta & 2.185 & 2.037 & 168 & 0.66 \\
\hline $\mathrm{Cu}^{2+}-2$-mercaptopropioni1-L-histidina & 2.256 & 2.043 & 76 & 0.51 \\
\hline $\mathrm{Cu}^{2+} \mathrm{N}$-mercaptoacetil-L-histidina & 2.301 & 2.069 & 93 & 0.65 \\
\hline $\mathrm{Cu}^{1+}, \mathrm{Cu}^{2+} \mathrm{DL}-$ Penicilamina & 2.414 & 2.080 & 123 & 0.87 \\
\hline $\mathrm{Cu}^{2+}-$ Glutationa & 2.221 & 2.062 & 190 & 0.88 \\
\hline
\end{tabular}

Tabela V - Parâmetros de RPE para complexos de $\mathrm{Cu}^{2+}$ com moléculas de amino-ācidos e peptídeos contendo enxôfre (Sugiura, 1975, 1976, 1977; Koslowski, 1977). 
Embora este cálculo seja bastante aproximado, ele serve para mostrar o considerāvel deslocamento eletrônico em direção aos ligantes, se o enxofre está ligado ao $\mathrm{Cu}^{2+}$. o complexo $\mathrm{Cu}^{2+}$ -N-mercaptoacetil-L-histidina (MAH), além de possuir $\left|A_{/}\right|$pequeno $(|A / /|=93$ gauss), mostra, tambēm, uma intensa banda de absorção( perto de $600 \mathrm{~nm}$ ), com absortividade de $830 \mathrm{M}^{-1} \mathrm{~cm}^{-1}$ explicada pe 10 autor (Sugiura, 1977), pela transição de transferencia de carga $\sigma(S) \rightarrow d(C u)$. A coordenação de cobre no complexo MAH 1:I, é parecida com aquela proposta por solomon (1976), para o cobre em plastocianina. Nos dois casos participam como ligantes, o enxofre, nitrogênios imidazol e peptídico. A simetria proposta nos dois complexos são diferentes $/$

Estes modelos estudados por Sugiura, são modelos com cô valencia e estão contrários à descrição de nãa covalencia dada por Brill e Bryce (1968). A presença do enxofre como ligante, é a causa principal para a grande deslocalização eletrônica, a qual ocasiona a diminuição de $\mathrm{A} / /$ e também explica a intensa cor azul do complexo. Existem, entretanto, outros complexos de $\mathrm{Cu}^{2+} \mathrm{com}$ penicilamina (Miyoshi, 1976), e glutationa em suas formas redu zida (Jezowska-Trzebiatowska, 1977) e oxidada (Kroneck, 1975), on de a ligação $\mathrm{Cu}^{2+}$ - s ocorre e, sua ligação covalente é pequena, como em outros complexos axiais (com $\alpha^{2}>0.8$ ) e com valor de $A_{/,}>100$ gauss, embora 0 valor de $A_{/ 2}$ para a penicilamina seja rela tivamente baixo. (132 gauss). A sugestão é que a covalencia da ligação $\mathrm{Cu}^{2+}$ - $\mathrm{S}$ pode depender das outras coordenaçōes, ou que a simetria tetragonal assumida por sugiura não está correta e, as sim, os valores do parāmetro $\alpha^{2}$, estão incorretos.

Uma outra característica dos espectros de RPE em proteínas azuis, bem como de outras proteínas, além do pequeno valor de A/, é a baixa simetria dos tensores $\overline{\overline{\mathrm{A}}}$ e $\overline{\bar{g}}$ (T.Vanggard, 1972). Em complexos com pequenos peptídeos, a distorção do plano na si - 
petria quadrado planar ou tetragonal é, geralmente, muito pequena, com o espectro de RPE apresentando simetria axial. Em prote nas, o arranjo estereoquímico para a coordenação do ion, não é Iivre, devido aos vínculos estruturais e, a simetria do complexo pode ser mais baixa que axial.

A possível influência de cadeias laterais maiores, em pequenos peptideos podem, em princîpio, gerar distorções na sime tria do complexo e, desta forma, gerar dados espectroscōpicos mais próximos de proteínas que apresentam tais distorções. Estudos neste sentido têm sido apresentados por Kozlowski (1978),com uma série de dipeptídeos constituidos de Glicil-X onde, X é um amino-ácido contendo uma cadeia lateral grande, próximo ao c-ter minal. Espectros de RPE de complexos de $\mathrm{Cu}^{2+}$ com estes dipepti deos, mostram simetria axial em uma faixa de $\mathrm{pH}$ até próximo de $\mathrm{pH}=11$ (Kozlowski, 1977), e os valores de A/ estão em concorāancia com outros complexos de peptídeos com $\mathrm{Cu}^{2+}$. Complexos de $\mathrm{Cu}^{2+}$ com dipeptideos, nesta faixa de pH são, geralmente, quelatos tri dentados com os grupos $\mathrm{NH}_{2}, \mathrm{~N}^{-}$amida e $\mathrm{COO}^{-} \mathrm{e}$, o quarto ligan te, geralmente, uma água.

Em $\mathrm{pH}$ acima de 12, a simetria do espectro de RPE de todos os complexos Gly-X, distorcem para uma simetria rómbica, exceto complexos de $\mathrm{Gly}-\mathrm{Gly}$ com $\mathrm{Cu}^{2+}$. A explicação desta quebra de simetria tem sido dada pelo rompimento da ligação do ion com o oxi gênio da Carboxila, por razões estéricas;, provocados pelo alto valor de pH (Kozlowski, 1977 e 1978; Kaneda, 1977). A Tabela VI resume os resultados espectroscópicos de RPE, mostrando o decréscimo con siderāvel de $A_{/ /}$ou $A_{z}$ com o aumento simultāneo de $\left|g_{x}-g_{y}\right| e$ $A_{\mathrm{x}}$

O argumento usado por Kozlowski (1978). na importância. da cadeia lateral pesada, pode ser vista na Tabela VI pelo grau de distorção $\left|g_{x}-g_{y}\right|$ crescente com o tamanho do resíduo la- 


\begin{tabular}{|c|c|c|c|c|c|c|c|}
\hline IIGANTES & $\mathrm{pH}$ & $g_{x}$ & ${ }^{g_{y}}$ & $g_{z}=g$ & $\begin{array}{l}A x \\
\text { (gauss) }\end{array}$ & $\begin{array}{c}A_{z}=A \\
\text { (gauss) }\end{array}$ & $g_{x}-g_{y}$ \\
\hline Phe-GIy & 13.1 & 2.070 & 2.050 & 2.215 & 30 & 160 & 0.020 \\
\hline Gly-Asp & 12.6 & 2.130 & 2.030 & 2.246 & 52 & 129 & 0.100 \\
\hline Gly-Met & 13.6 & 2.126 & 2.016 & 2.257 & 25 & 123 & 0.110 \\
\hline Met-Val & 13.6 & 2.122 & 2.014 & 2.259 & 30 & 123 & 0.100 \\
\hline D-Leu-Tyr & 13.1 & 2.096 & 2.001 & 2.282 & 50 & 110 & 0.095 \\
\hline$G I y-G l u$ & 12.5 & 2.142 & 2.025 & 2.252 & 61 & 107 & 0.117 \\
\hline Gly-Tyr & 12.6 & 2.155 & 2.015 & 2.267 & 70 & 98 & 0.140 \\
\hline Gly-Phe & 13.1 & 2.151 & 2.020 & 2.270 & 67 & 95 & 0.131 \\
\hline Ala-Tyr & 13.1 & 2.153 & 2.005 & 2.274 & 74 & 79 & 0.148 \\
\hline
\end{tabular}

Tabela VI - Parâmetros de RPE de complexos de $\mathrm{Cu}^{2+}$ com aipeptídeos com cadeia lateral pesada, na região de alto $\mathrm{pH}$ (Koslowski, 1978). 
teral. Por exemplo, nos complexos onde as cadeias laterais con tendo anéis aromāticos no lado Ć-terminal (Gly-Tyr, Gly-Phe; Ala$-T y r)$, os valores de $A_{\|}$são os menores e os valores de $\left|g_{x}-g_{y}\right|$, os maiores. 
CAPITULO II

\section{MATERIAIS E METODOS}

\section{TECNICAS EXPERIMENTAIS}

No estudo de complexos de ions de cobre com amino-ácidos, peptídeos e proteínas, várias técnicas têm sido utilizadas, tais como titulação potenciométrica, "stopped-flow" e relaxação na obtenção de constantes de equilíbrios químicos, absorção ōtica ou transições eletrōnicas, visível e ultravioleta, bem como Ressonân cia Paramagnētica Eletrōnica (RPE), para caracterização dos complexos formados. Técnicas de absorção no infravermelho, permitem caracterizar, pelos modos vibracionais, ligações como metal-1i gante, identificando, assim, ligantes como o enxofre de grupos sulfidrílicos, nitrogênios amida e amina, e oxigênios de grupos carboxilatos.

Neste trabalho, utilizamos as tēcnicas de absorção ótica e RPE, e tentamos mostrar a complementaridade das técnicas de RPE e absorção ótica, na caracterização dos complexos formados.'

\section{PREPARAÇÃO DAS AMOSTRAS}

O dipeptídeo utilizado (Glicil-Tritofano) para a comple xação com ion de $\mathrm{Cu}^{2+}$, foi adquirido na "Sigma Chemical Company" com peso molecular igual a 261,3 daltons (peso anhidroi

A razão da escolha deste dipeptideo foi, justamente, por apresentar o residuo lateral grande e pesado do triptofano, e ver seu efeito sobre simetria do complexo, formado em pH acima de 11, como afirma Kozlowski (1978).

A fórmula estrutural do Glicil-Triptofano em sua forma Zwiteriōnica está mostrada na figura 3 .

O dipeptídeo foi dissolvido em uma solução de NaOH 0,5M 
para obter-se uma concentração do dipeptídeo de $100 \mathrm{mM}$. Tomou -se $10 \mathrm{ml}$ desta solução e adicionou-se $10 \mathrm{ml}$ de uma solução de $\mathrm{CuCl}_{2} \quad 10 \mathrm{mM}$, obtendo-se uma relação ligante-metal de 10:1.

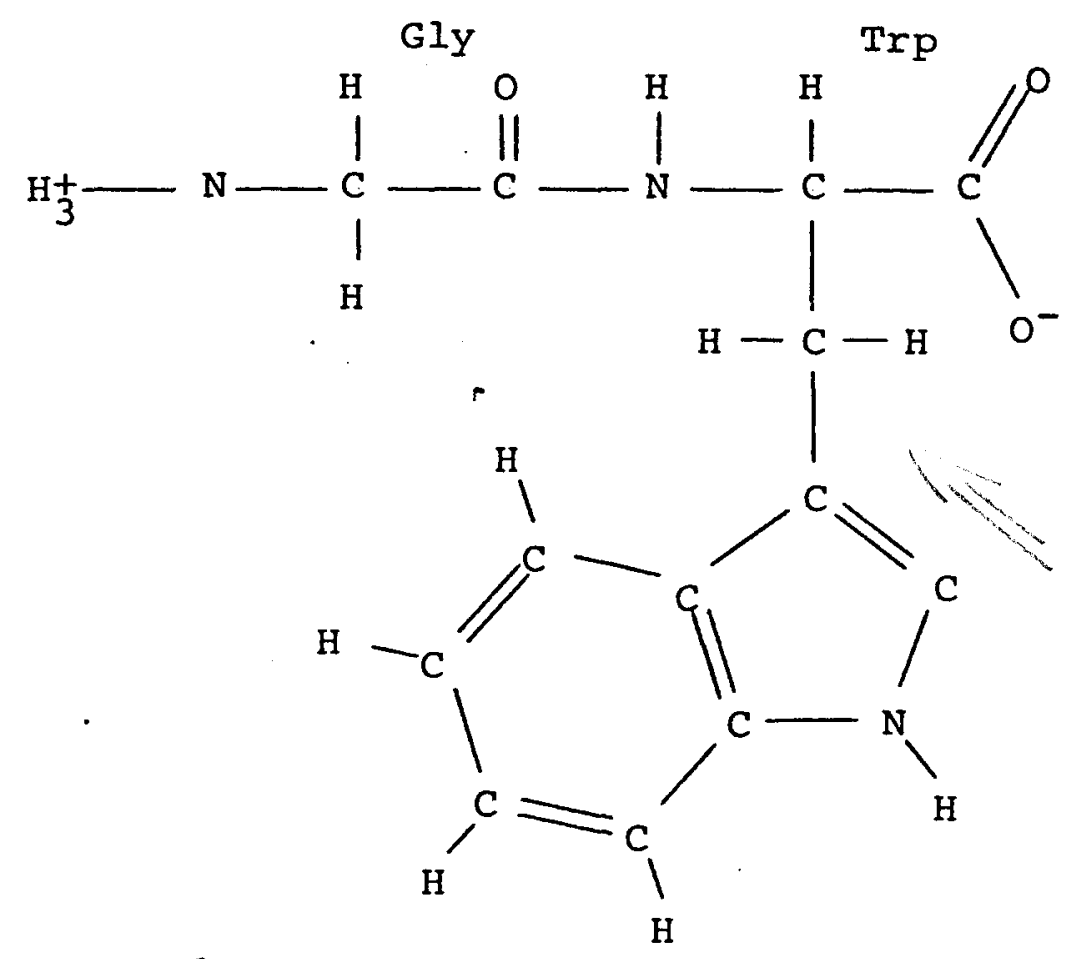

Fig.3 - Fórmula estrutural do dipeptîdeo Glicil-Triptofano em sua forma zwiteriónica.

Ao adicionar o metal ao ligante formou-se, imediatamente, uma so lução de coloração azul bem forte, caracterizando a ,complexação imediata do ion $\mathrm{Cu}^{2+}$. $\mathrm{O}$ pH da solução assim obtida, é de 13,20. Com a utilização de um pH-metro da corning, modelo 130 , o pH da solução foi variado, utilizando-se solução de HCl, desde 13,20 até 2,50 e alíquotas de $0,5 \mathrm{ml}$. coletadas a cada 0,5 unidades de $\mathrm{pH}$. Estas amostras foram utilizadas para as medidas de absorção eletrônica no visível (faixa entre $350 \mathrm{~nm}$ e $1100 \mathrm{~nm}$ ), e medidas de ressonância paramagnética eletrônica em duas tem peraturas, ambiente e nitrogênio líquido. As medidas foram feitas imediatamente após a preparação, para evitar possíveis mo dificações nas amostras. Um controle foi feito utilizando-se os próprios espectros de RPE e absorção, para ter certeza da quali dade da amostra. Enquanto utilizadas, as amostras foram manti das a 49 C e mudanças nos espectros foram observadas, especial- 
mente nas amostras de $\mathrm{pH}$ muito alcalino, depois de alguns dias. Observou-se ainda que, entre os pHs 7.50 e 5.00, há a formação de pequenos cristais em forma de lâminas bem delgadas, triangulares claras que, filtradas, secadas e analisadas por RPE nos permite concluir que devem ser cristais do dipeptídeo não complexado.

Na tentativa de obter cristais dos complexos formados preparou-se soluçōes com estequiometrias ligante-metal nas ra zões $2: 1$ e $1: 1$ em diferentes pHs $(12.20,9.20,5.00)$, obtendo -se sempre a rápida formação de cristais azul forte em todás elas, sendo que na solução de $\mathrm{pH}=5.00$, na relação $2: 1$, depois de separado por filtragem os cristais azul-forte, restou uma so lução de cor azul clara. Desta forma só conseguimos obter cristais de apenas um dos complexos formados.

\section{EQUIPAMENTOS UTILIZADOS}

Utilizou-se, para as medidas de absorção óptica no visivel, o espectro-fotômetro Varian $\mathrm{DK}-2$ medindo-se as bandas cor respondentes às transições $\mathrm{d}-\mathrm{d}$ dos complexos de $\mathrm{Cu}^{2+}-\mathrm{Gly}$-Trp em função do pH. A faixa de comprimentos de onda varrida foi de $350 \mathrm{~nm}$ a $1100 \mathrm{~nm}$.

Para as medidas de RPE utilizou-se um espectrômetro Varian da linha E-Century E-109 que trabalha em banda $x(9.3 \mathrm{GHz})$ utilizando uma cavidade retangular (multi-purpose cavity E-231) com o sistema de controle de temperatura da Varian Modelo $E-257$ para medidas à temperatura de $-1509 \mathrm{C}$. A modulação do sinal foi feita em $100 \mathrm{kHz}$ com amplitude de 4 gauss pico a pico, e a potên cia de microondas utilizada foi de $10 \mathrm{~mW}$. Testes de potência foram feitos para melhorar a resolução das linhas super-hiperfi nas devida a nūcleos de nitrogênios complexados com o ion $\mathrm{Cu}^{2+}$. 
Para as medidas do espectro de RPE do mono-cristal do complexo cristalizado utilizou-se a cavidade cilindrica Varian modelo E-233 e os parâmetros de RPE foram calculados com ajustes feitos utilizando-se o computador PDPll/45. 


\title{
CAPITULO III
}

\author{
RESULTADOS
}

1. ESPECTROS DE ABSORÇÃO ELETRONICA NO VISIVEL

E bastante conhecida as transições eletrōnicas de complexos de $\mathrm{Cu}^{2+}$ com amino-ácidos e peptídeos, na região do visí vel. Geralmente as bandas de absorção são largas e ao redor de $600 \mathrm{~nm}\left(\sim 16.000 \mathrm{~cm}^{-1}\right)$ correspondentes a transições $d-d$, transi çōes, estas, permitidas devido a acoplamentos com modos vibracio nais essencialmente.

As simetrias dos campos cristalinos comuns, que aparecem nestes tipos de complexos, são tetragonal e quadrado planar, com pequenas distorções. A razão disto é que os ligantes mais co muns nestes complexos são àtomos de nittrogênios e oxigênios, como relatados no Capítúlo I, que são vinculados pelas ligações con átomos de carbonos, formando planos bem definidos. Pode-se obser var, entretanto, que complexos só com oxigênios ou só com Nitrogênios em simetria auadrado planar dão bandas de absorção em com primentos de. ondas diferentes sendo mais comuns os valores ao re dor de 640 e $550 \mathrm{~nm}$ respectivamente.

Nos complexos de $\mathrm{Cu}^{2+}$ com dipeptídeos, é frequente ter dois ligantes nitrogênios (amina e amida), e dois oxigênios (car boxila e àgua).

Para espectros obtidos de soluções dos complexos, exis tem poucas situações onde é possivel observar mais de uma banda, já que a largura da mesma não permite resolver todas as transi ções $d-d$.

Nos complexos de Gly-Trp com Cu${ }^{2+}$ em solução, foram feitas medidas de absorção óptica desde o $\mathrm{pH}=2.50$ até $\mathrm{pH}=13.20$, na faixa de comprimentos de ondas compreendidos entre $350 \mathrm{~nm}$ $1100 \mathrm{~nm}$. A figura 4 mostra atagans 


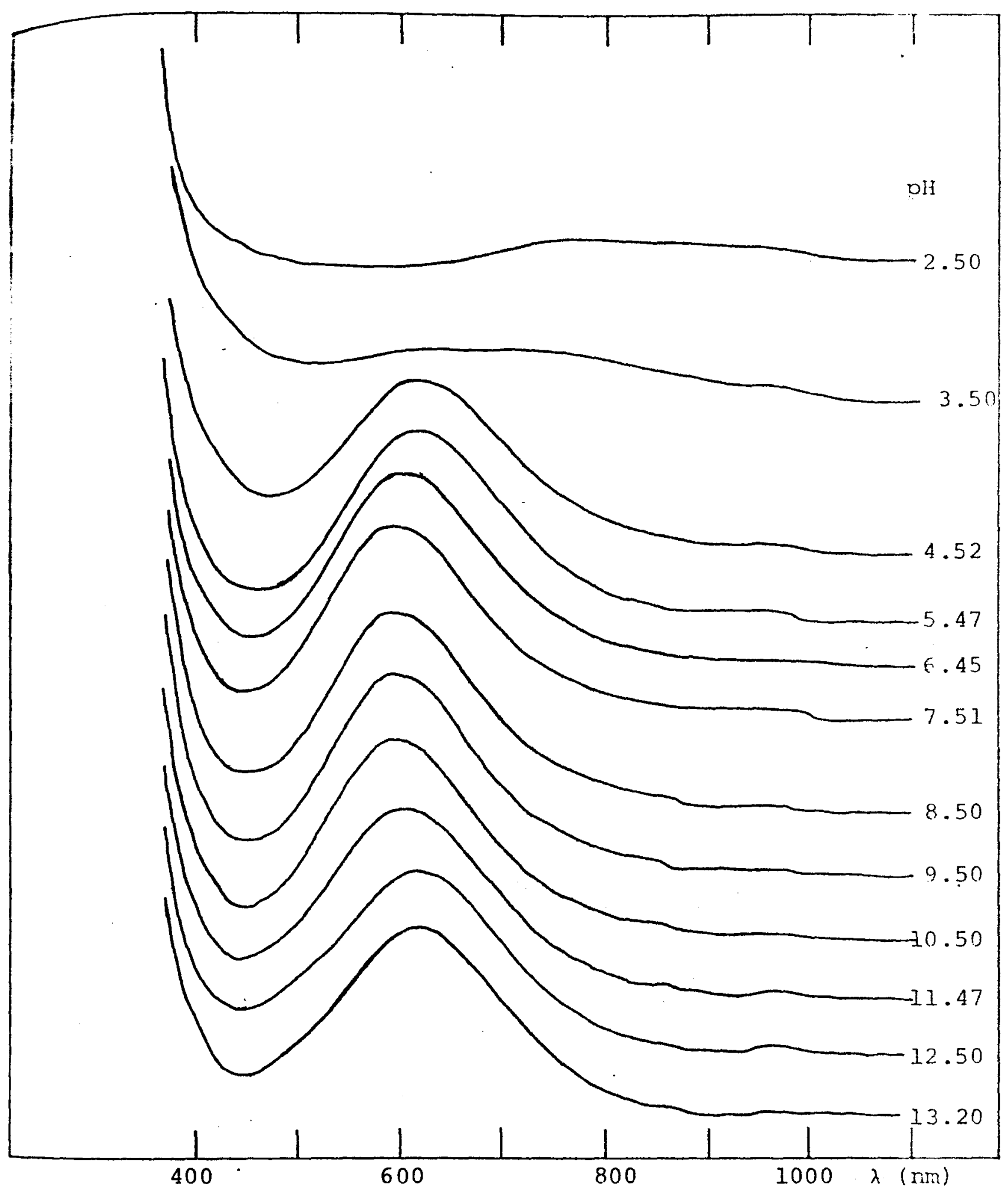

Fig 4 - Espectros de absorção eletrônica dos complexos $\mathrm{Cu}^{2+}-\mathrm{Gly}$ - Trp em função do $\mathrm{pH}$ das soluções. 


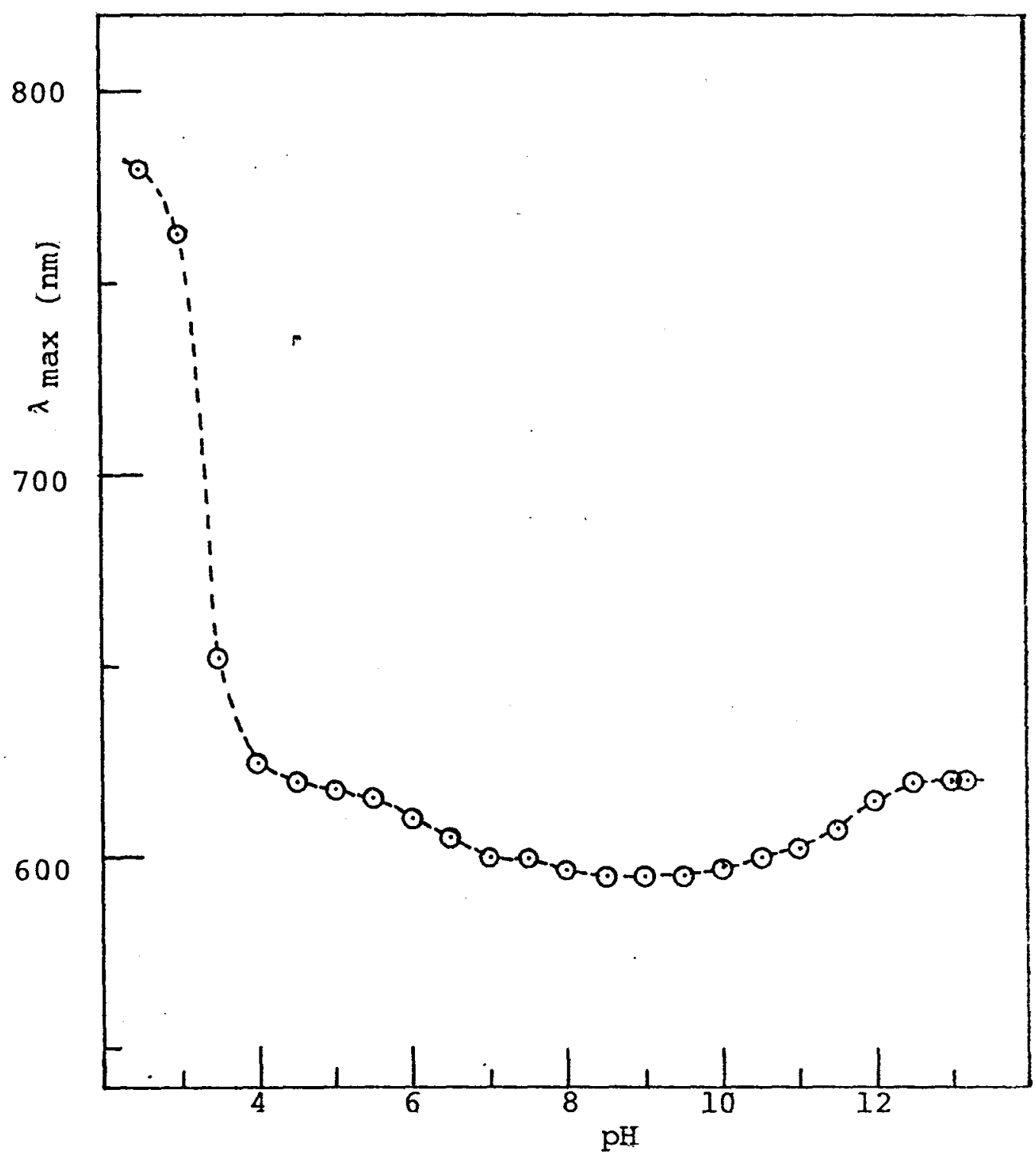

Fig. 5 - Grä́fico do comprimento de onda correspondente ao máximo da banda de absorção dos espectros eletrônicos dos complexos $\mathrm{Cu}^{2+}$ - Glicil - Triptofano em função do pH das soluçôes. 
agerindo ou mudança no campo cristalino, ou aparecimento e desaparecimento de espécies distintas de complexos.o gráfico apresentado na figura 5, mostra a variação do comprimento de onda do máximo da banda em função do pH.

observando a figura 5, e supondo a existência de espé cies distintas de complexos, já que o crescimento do $\mathrm{pH}$ produz a dissociação de protons dos diferentes grupos ionizáveis nos eus res pectivos pKs (em presença do ion), devemos esperar a existência de, pelo menos, 4 (quatro) espécies de complexos. O primeiro, a pH muito baixo $(-2.5$ o segundo ao redor de $\mathrm{pH}=5.0$, o terceiro ao redor de $\mathrm{pH}=9.0$, 0 qual deve existir em uma faixa ampla de $\mathrm{pH}$ (entre 6.0 e 11.0 ) e, finalmente, o último, acima de $\mathrm{pH}=12.0$.

Em pH muito baixo (da ordem de 2.5), todos os grupos que apresentam protons dissociāveis estão protonados e o ion deve estar coordenado com água, dando, por isto mesmo, uma banda mui to larga com absortividade pequena e com' $\lambda$ maximo perto de $800 \mathrm{~nm}$ caracteristicas do ion dissolvido em àgua.

Em $\mathrm{pH}$ ao redor de 5,00 já é esperado que grupos carboxí licos e grupos aminas já estejam, na presença dos ions de $\mathrm{Cu}^{2+}$, desprotonados (veja Tabela II e figura 1), e complexos com a proporção de dois ligantes para um metal jä podem ocorrer, uma vez que um grande excesso do ligante foi utilizado na preparaçäo das amostras ( $10 \mathrm{~L}: \mathcal{L}$ M). Devemos esperar, então, o ion complexado com um nitrogènio e um oxigènio por peptídeo.

Para pHs maiores que 6.00 já estão desprotonados, na pre sença do ion de cobre, os nitrogênios peptídicos e então, o quela to formado pelos dois nitrogênios amina e peptídico, e pelo oxi gênio da carboxila deverão estar presentes, sendo o quarto ligañte um oxigênio dêuma molécula de àgua.

E interessante observar que entre os pHs 5.00 e 7.50 , 
observou-se a precipitação de micro-cristais (em forma de làminas delgadas e triangulares), transparentes de dipeptideos onde não foi observada a existência de ions de cobre por RPE.

Em pHs acima de 12.0, é possível que a desprotonização do nitrogênio da cadeia lateral do triptofano possa induzir alguma mudança na estereoquimica, e ocorrer, como consequência, uma distorção no campo cristalino, ou mesmo até obrigar o oxigênjo da carboxila a descoordenar-se do complexo, como sugere Kozlowski ( 1978), e ser substituído por uma água ou um grupo $\mathrm{OH}^{-}$. Nestas con dições, é dificil esperar um complexo com simetria quadrado pla nar, sendo mais provável ter-se uma simetria tetraédrica com grandes distorções.

\section{ESPECTROS DE RESSONÂNCIA PARAMAGNETICA ELETRÔNICA}

Os espectros de RPE dos complexos aqui estudados, foram tomados em banda $\times(9.3 \mathrm{GH} z)$, em duas temperaturas : ambiente $\mathrm{e}$ $-150^{\circ}$ C. Os espectros à temperatura ambiente são promediados em suas dependências angulares devido ao movimento de rotação dos com plexos observando-se, de um modo geral, as 4 linhas correspondentes à interação hiperfina do spin eletrônico com o spin nuclear do próprio núcleo do ion $\mathrm{Cu}^{2+}$. Nestas circunstâncias, podemos extrair os valores dos parâmetros de RPE promediados corresponden tes aos tensores giromagnético $\overline{\bar{g}}$ e hiperfino $\overline{\bar{A}}$ que são dados a proximadamente pelos valores (ver apêndice):

$$
\begin{aligned}
& g_{0}=\frac{1}{3}\left(g_{1}+g_{2}+g_{3}\right)=\frac{1}{3}\left(g_{/ 1}+2 g_{1}\right) \\
& A_{0}=\frac{1}{3}\left(A_{1}+A_{2}+A_{3}\right)=\frac{1}{3}\left(A_{/ /}+A_{1}\right)
\end{aligned}
$$

Além disto, é possível observar.a existēncia de desdobramentos de linhas do espectro correspondentes a interações super -hiperfinas que possam exisitr com spin nucleares de núcleos vi - 


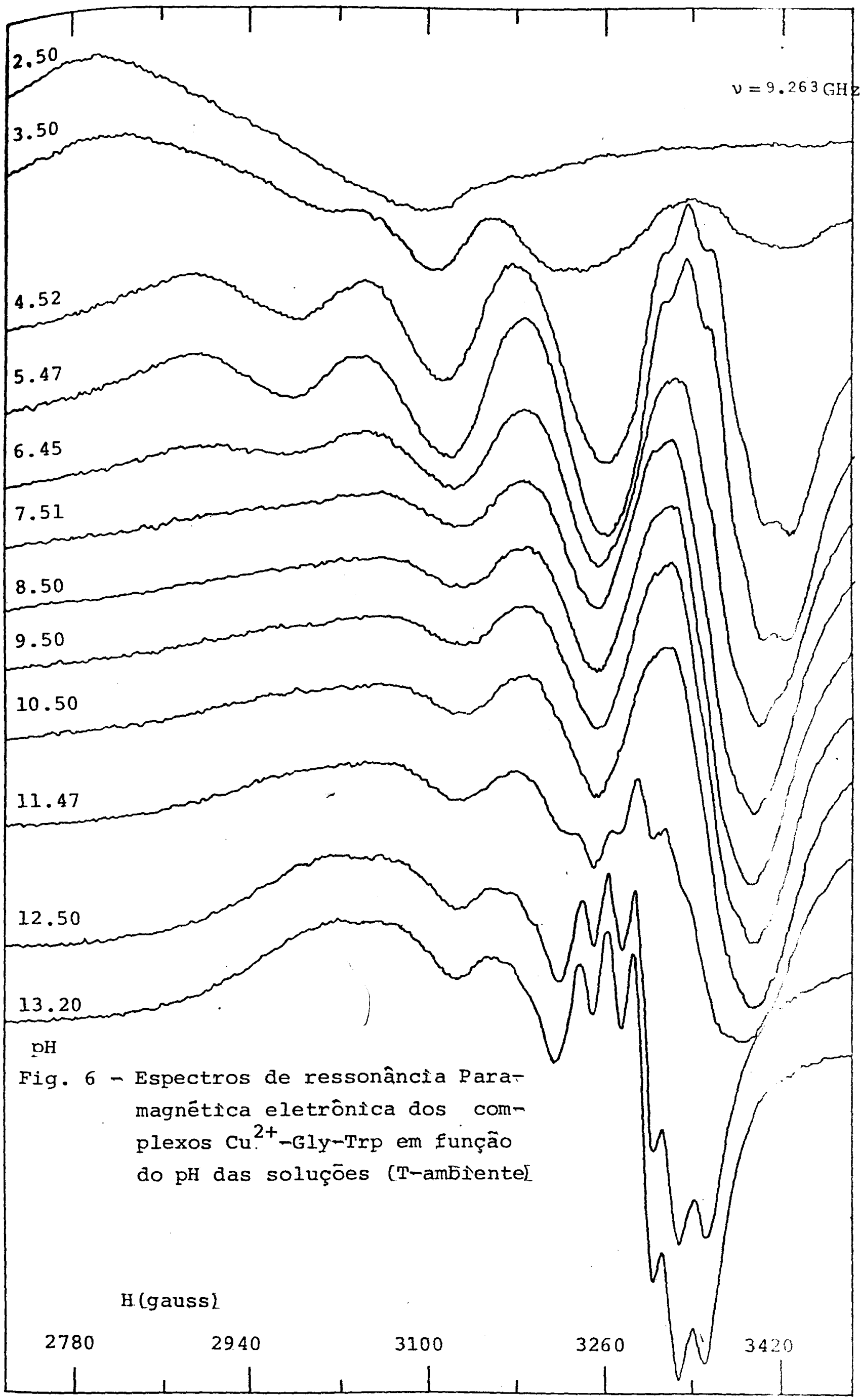


zinhos como, por exemplo, de nitrogênios. Neste caso é possivel saber o no. de núcleos equivalentes pelo no de linhas que ocorre no desdobramento, e a separação das linhas permite obter-seo valor promediado do tensor super-hiperfino $a_{N}$ (ver apêndice).

A figura 6 mostra os espectros de RPE à temperatura am biente dos complexos de $\mathrm{Cu}^{2+}-\mathrm{GlY}_{\mathrm{Y}} \mathrm{Trp}$ para vārios pHs.

Pode-se observar que entre os pHs 2.50 e 3.50 o espe ctro é basicamente constituído de uma linha larga (onde não se vê desdobramento hiperfinol, que è tipicamente o apresentado por ions de $\mathrm{Cu}^{2+}$ livres (coordenados por molécular de água) com mo vimentos suficientemente rāpidos para esconder a interação hiper fina.

Entre pHs 4.00 e 6.00 os espectros de RPE apresentam as 4 linhas do ion $\mathrm{Cu}^{2+}$ complexado com ligantes mais pesados que moléculas de água, portanto, com movimentso mais lentos, onde a linha de campo alto é desdobrada em 5 linhas adicionais, corres pondentes à interação super-hiperfina com dois nitrogênios equi valentes. O fato de, este desdobramento só aparecer na linha de campo mais alto pode ser associado ao caso de os nitrogēnios es tarem contidos no plane perpendicular ao eixo de simetria axial.

Entre os pHs 6,50 e 11.0, os espectros são semelhantes aos anteriores em relação à interação hiperfina, mas a interação super-hiperfina com nitrogênios não è mais claramente visível, pelo desdobramento da linha de campo alto. Uma observação mais cuidadosa entretanto, mostra que esta linha tem alguma estrutu ra que, em princípio, pode ainda ser explicada pela existência dos dois nitrogēnios em posições não equivalentes e, por esta razão, escondidos pela largura e superposição dos dois tripletes não equi valentes. E conhecido que a distânica mēdia $\mathrm{Cu}-\mathrm{N}$ de nitrogênios peptídicos está em torno de $1.92 \AA$, enquanto que, para nitrcgênios do terminal amina é de $2.00 \AA$. 


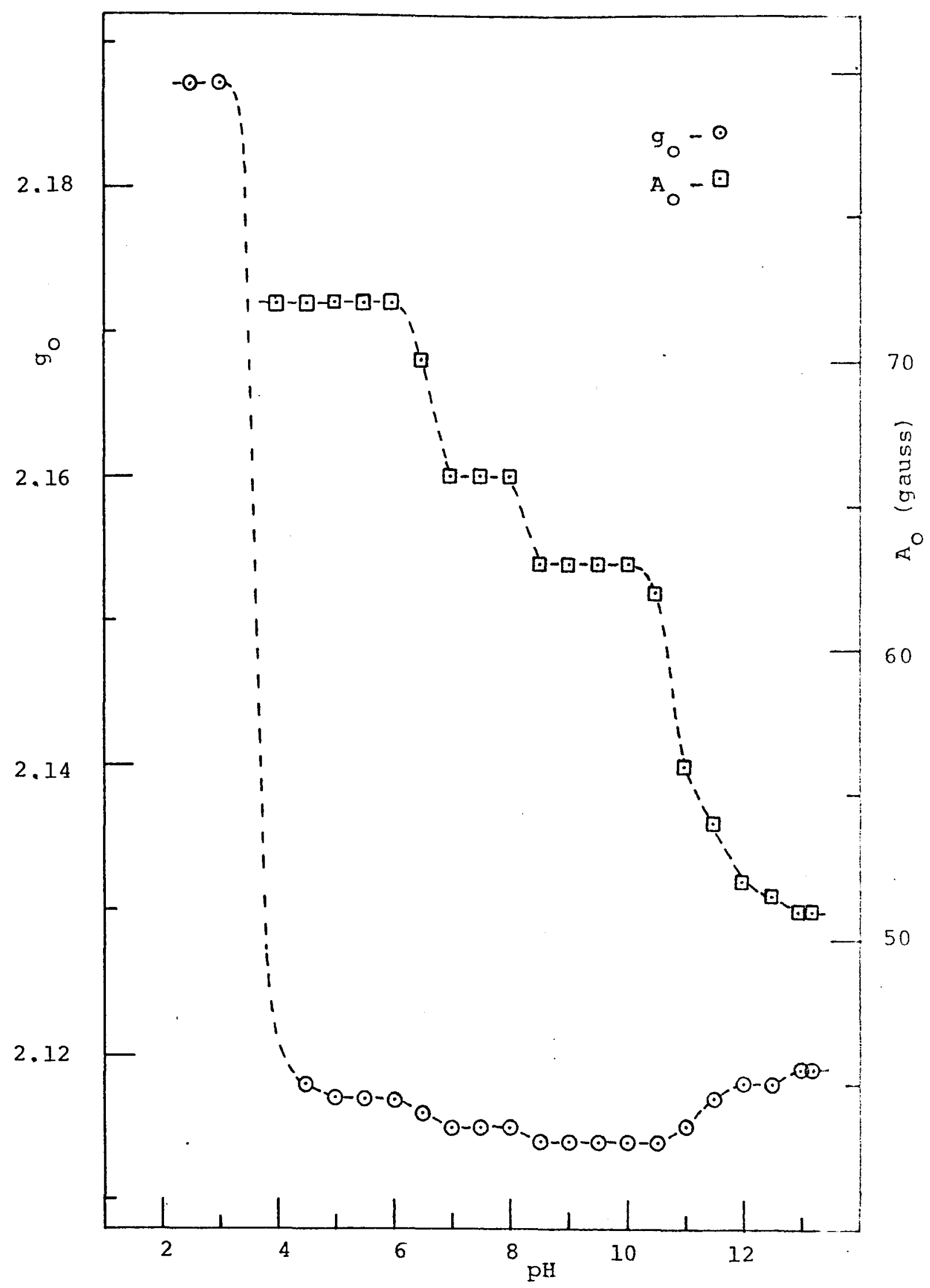

Fig. 7 - Gräfico dos parâmetros $g_{0}$ e $A_{0}$ dos complexos $\mathrm{Cu}^{2+}-\mathrm{Gly}-$ -Trp em funçāo do $\mathrm{pH}$ das soluçōes, medidos à T-ambiente. 


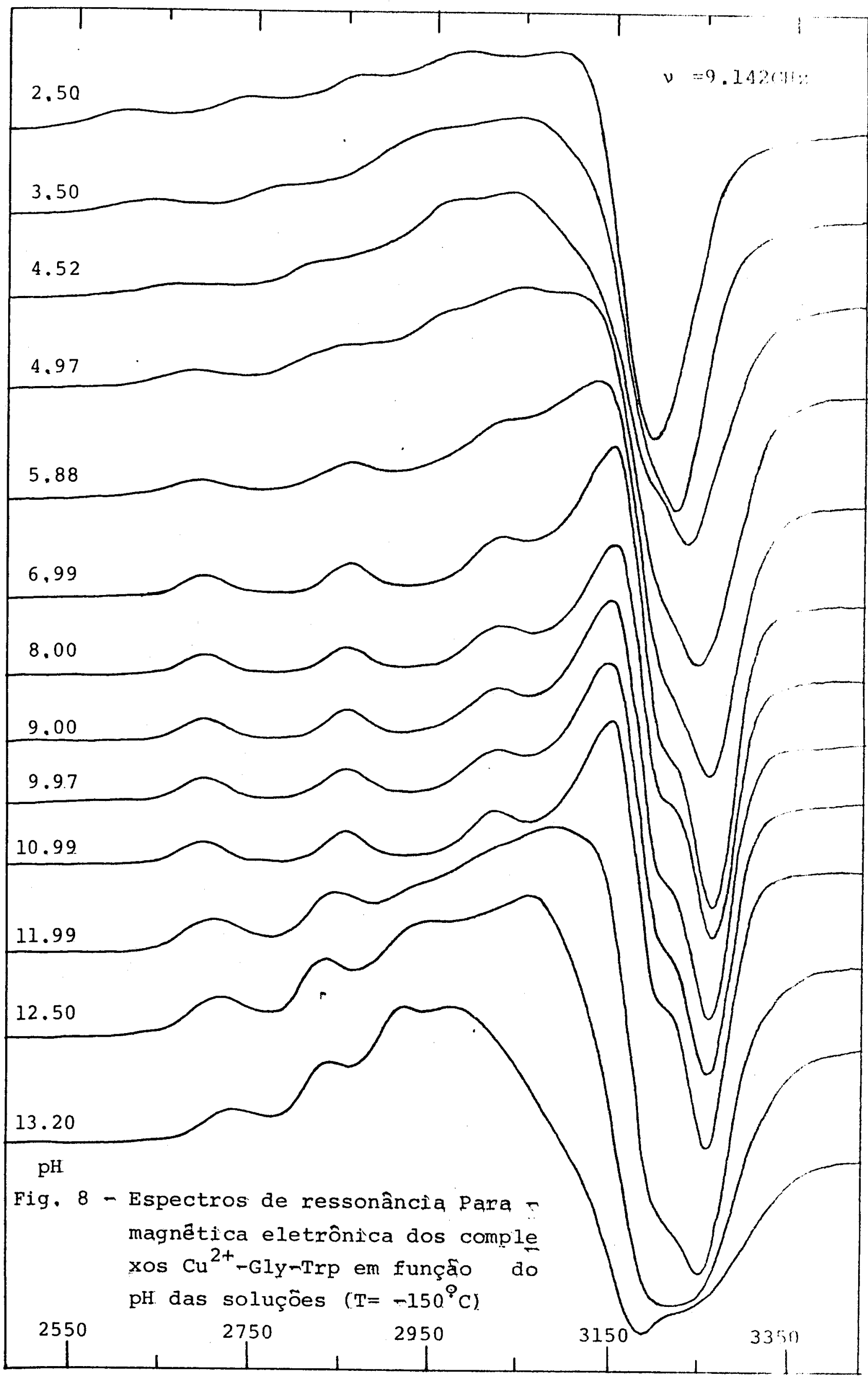




\begin{tabular}{|c|c|c|c|c|c|c|c|c|}
\hline $\mathrm{pH}$ & $9_{0}$ & $\begin{array}{c}\mathrm{A}_{0} \\
\text { (gaus's) } \\
\end{array}$ & ${ }_{\mathrm{N}}^{\mathrm{N}_{\mathrm{N}}}$ & $g_{/ 1}$ & $g_{\perp}$ & $\begin{array}{c}\text { A } / / \\
\text { (gauss) } \\
\end{array}$ & $\begin{array}{c}A_{\perp} \\
\text { (gauss) }\end{array}$ & $\begin{array}{l}x_{\max } \\
(\mathrm{nm})\end{array}$ \\
\hline 2.50 & 2.187 & & & 2.327 & 2.117 & 133 & & 780 \\
\hline 2.97 & 2.187 & & & & & 133 & & 763 \\
\hline 3.50 & & & & & & & & 6.52 \\
\hline 4.00 & & $72(?)$ & $12.5(?)$ & & & & & 625 \\
\hline 4.52 & 2.118 & 72 & 12.5 & 2. 259 & & 150 & 33 & 620 \\
\hline 4.98 & 2.117 & 72 & 12.5 & 2.258 & & 150 & 33 & 113 \\
\hline 5.48 & 2.117 & 72 & 12.5 & 2.252 & & & & 61.8 \\
\hline 5.88 & 2.117 & 72 & 12.5 & 2.223 & & & & 61.0 \\
\hline 6.45 & 2.116 & 70 & & 2.223 & & 162 & 24 & 6.115 \\
\hline 6.99 & 2.115 & 66 & & 2.223 & & 161 & 18.5 & 600 \\
\hline 7.51 & 2.115 & 66 & & 2.223 & & 161 & 18.5 & 597 \\
\hline 8.00 & 2.115 & 66 & & 2.224 & 2.061 & 161 & 18.5 & 505 \\
\hline 8,51 & 2.114 & 63 & & 2.225 & 2.059 & 160 & 14.5 & 505 \\
\hline 9.00 & 2,114 & 63 & 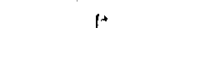 & 2.226 & 2.058 & 160 & 14.5 & 5,15 \\
\hline 9.51 & 2.114 & 63 & & 2.227 & 2.058 & 160 & 14.5 & 507 \\
\hline 9.97 & 2.114 & 63 & & 2.227 & 2.058 & 160 & 14.5 & 600 \\
\hline 10.50 & 2,114 & 62 & & 2.227 & & 160 & 13 & 602 \\
\hline 10.99 & 2.115 & 56 & $13.5(?)$ & 2.227 & & 160 & & 607 \\
\hline 11.48 & 2.117 & 54 & 13.5 & 2.230 & & 156 & & $6] 5$ \\
\hline 11.99 & 2.118 & 52 & 13.5 & 2.244 & & 137 & & 620 \\
\hline 12.50 & 2,118 & 51 & 13.5 & 2.260 & & 115 & 19 (?) & 6,20 \\
\hline 13.00 & 2.119 & 51 & 13.2 & 2.260 & & 111 & $21(?)$ & 0.20 \\
\hline 13.20 & 2.119 & 51 & 13.2 & 2,260 & & 106 & $24(?)$ & 620 \\
\hline $\begin{array}{l}\text { Cristal } \\
\text { Nalores } \\
\text { médios) }\end{array}$ & 2.107 & & & 2,185 & $\begin{array}{l}2.082 \\
2.054\end{array}$ & & & \\
\hline $\begin{array}{l}\text { Cristal } \\
\text { (valores } \\
\text { molecula } \\
\text { res) }\end{array}$ & 2.109 & & & 2.212 & $\begin{array}{l}2.078 \\
2.036\end{array}$ & & & \\
\hline $\begin{array}{l}\text { Policris } \\
\text { tal }\end{array}$ & 2.110 & & & 2.182 & 2.074 & & & \\
\hline $\begin{array}{l}5.00^{*} \\
\text { - Calcula }\end{array}$ & $\begin{array}{l}2.117 \\
\text { ado a } \mathrm{F}\end{array}$ & $\begin{array}{l}73.7 \\
\text { tir dos }\end{array}$ & $\begin{array}{c}12,5 \\
\text { os espe }\end{array}$ & 2,259 & $\begin{array}{l}2.046 \\
\text { ferenças }\end{array}$ & $\begin{array}{l}154 \\
- \text { figs. }\end{array}$ & $\begin{array}{r}33.5 \\
.9,10 \mathrm{e} \\
\end{array}$ & $\begin{array}{r}640 \\
=11 .\end{array}$ \\
\hline
\end{tabular}

Tabela VII - Valores dos parâmetros espectroscópicos de RPE e absorção eletrônica para os complexos de $\mathrm{Cu}^{2+}-\mathrm{Gly}-\mathrm{Trp}$ 
Acima de $\mathrm{pH}=11.0$ é possível observar novamente 0 apare cimento de 5 linhas bem nítidas na posição da linha de canpo alto, correspondentes à interação super-hiperfina com dois nitro gênios equivalentes. Os päâmetros de ressonância destes cspe ctros são diferentes daqueles apresentados pelo complexo ao re dor de $\mathrm{pH}=5.0$. As linhas super-hiperfinas são melhor resolvidas,

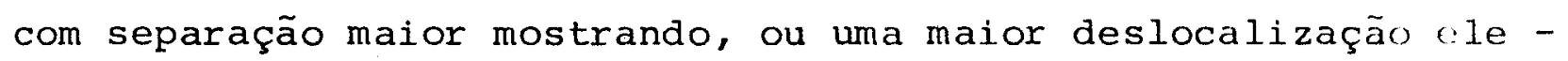
trōnica do ion, ou uma equivalencia maior (menor distorção), entre os dois nitrogènios.

Estes resultados estão em pleno acordo com a existên cia de quatro espécies distintas como sugeridas pelos dados de espectrofotometria.

Os parâmetros destes complexos estão apresentados

na Tabela VII, e graficados na figura 7 .

Os espectros de RPE foram medidos também à temperatura de $-150^{\circ} \mathrm{C}$ para obtenção dos parāmetros de ressonāncia e niclhor informação da simetria do campo cristalino visto pelo ion $\mathrm{Cu}^{2+}$. A figura 8 mostra estes espectros para os diferentes pHs. Pode- se observar que a esta temperatura, as linhas super-hiperfinas não são resolvidas devido à superposição das linhas em campo al to. Por outro lado nos espectros congelados a esta temperatura, fica bem evidente a superposição de espectros de espécies diferentes permitindo, portanto, uma melhor caracterização dos complexos formados e suas misturas.

Entre os pHs 2.5 e 3.5 , é bem clara a dominância da espécie ion $\mathrm{Cu}^{2+}$ complexado com água, sendo já nîtida a super posição de espectro do complexo $2 \mathrm{~L}:$ IM que predomina em $\mathrm{pH}=5.00$ que, por sua vez, já contem superposição do espectro do complexo tridentado que existe predominantemente entre os pHs 6.5 e 11.0. Acima de $\mathrm{pH}=11.0$, já se pode notar a mudança do espectro, que fica bem caracterizado em $\mathrm{pH}=13.20$, onde o parâmetro de in- 


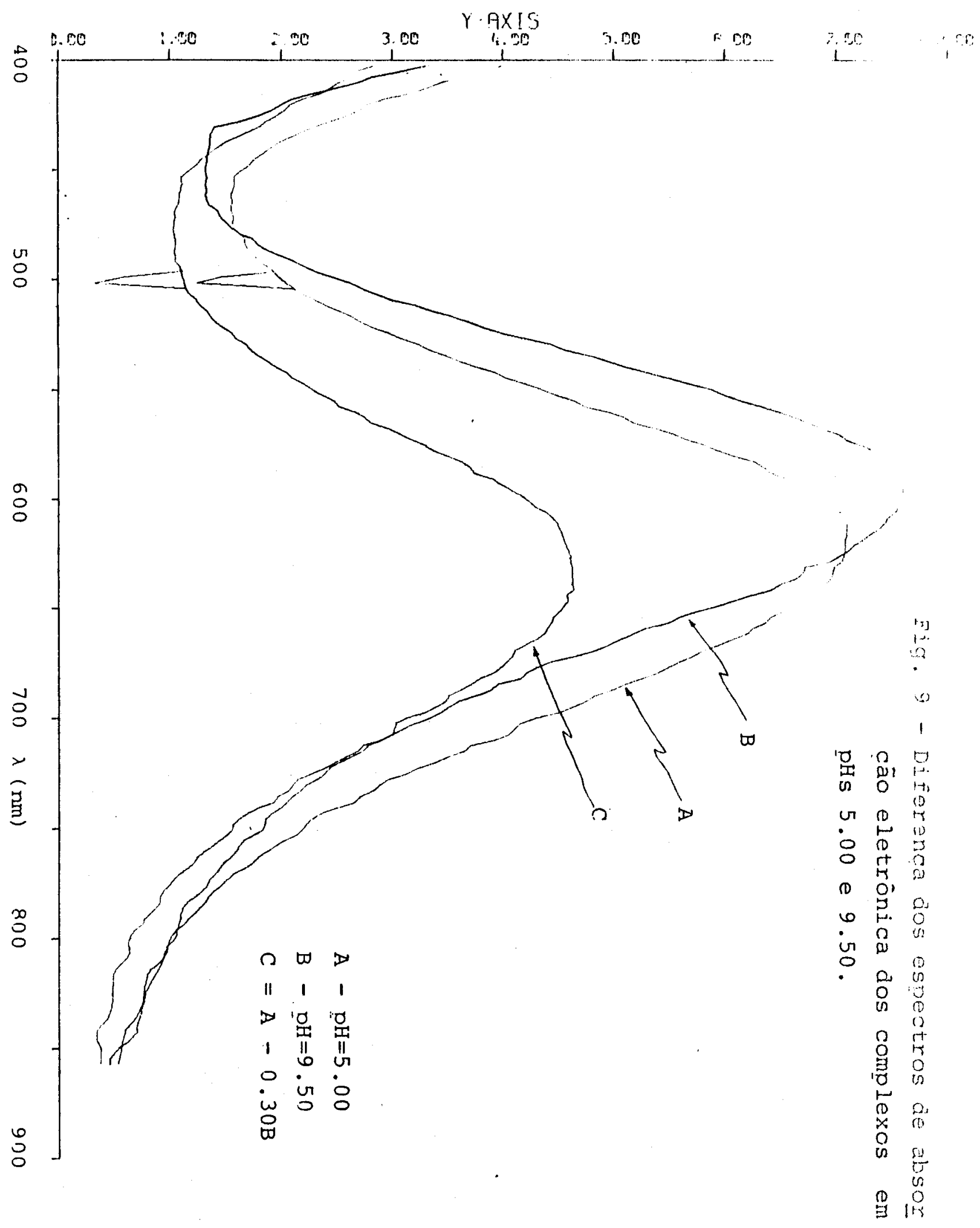




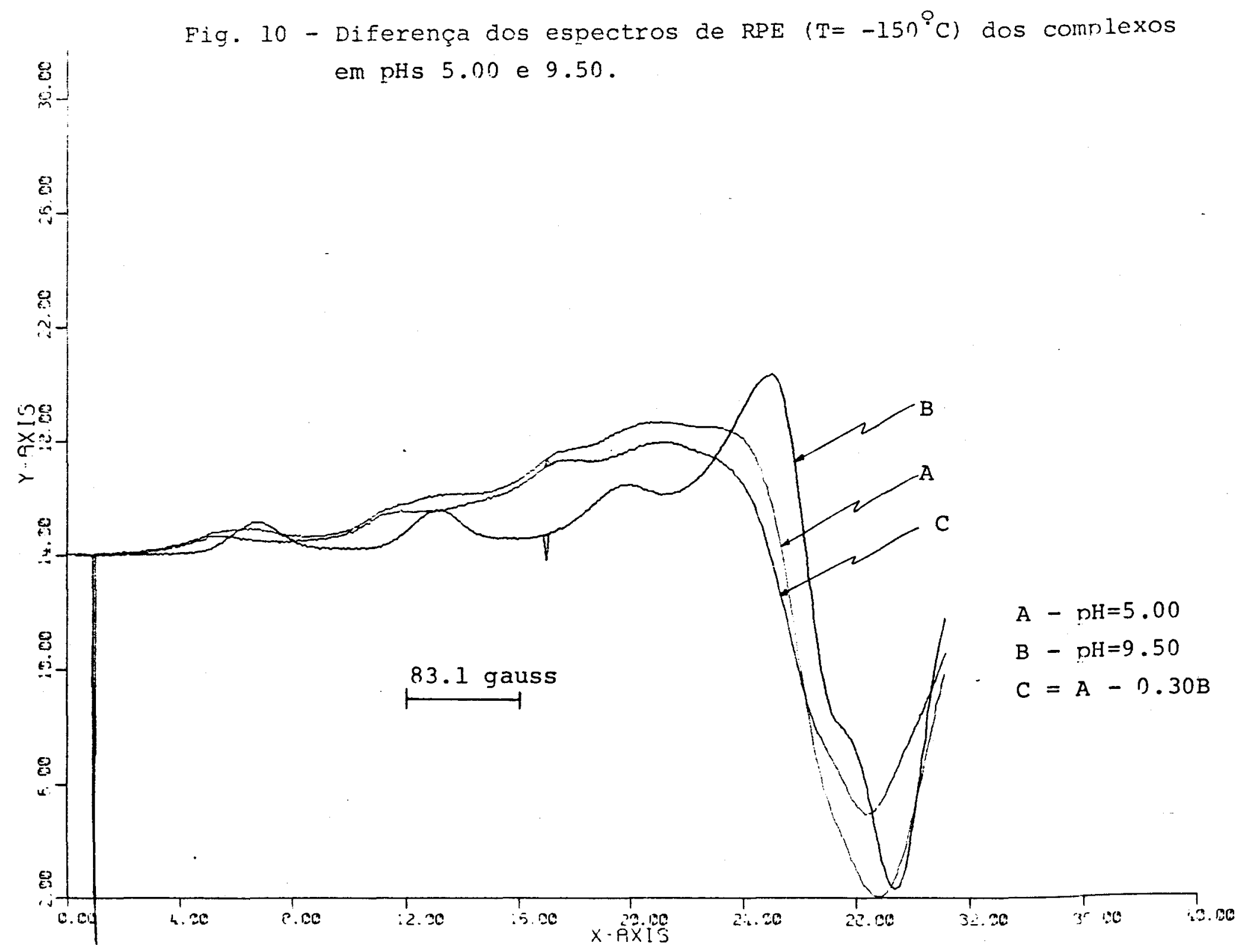




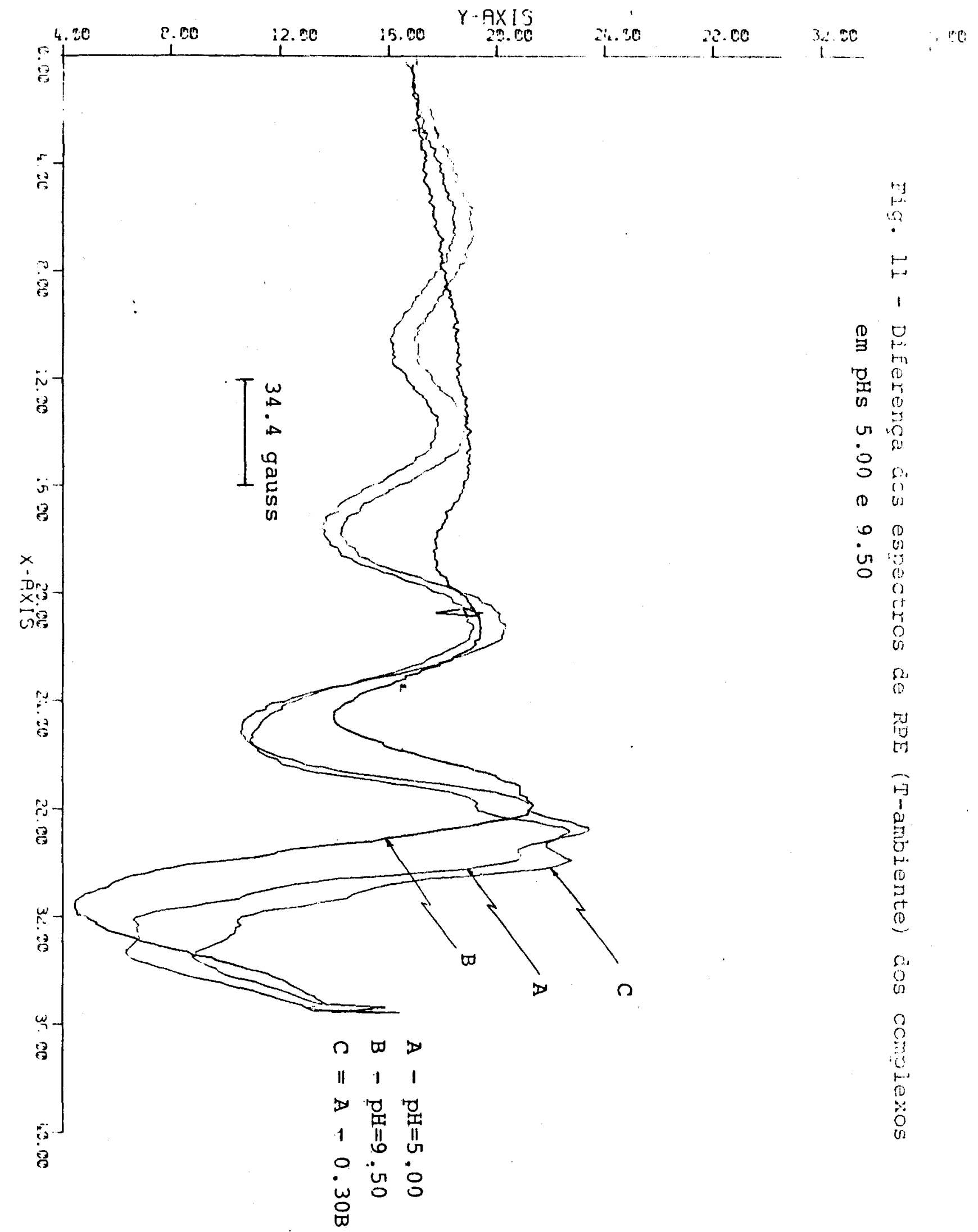

IFSG - SEFVICO DE EIELIOTECA E
INFORMACAO 
teração hiperfina $A_{\text {, }}$ ou $A_{z}$ é bem menor que nos outros compluns (região de campo baixo). Na região de campo alto, a forma cspectral é explicada se assumirmos uma simetria mais baixa que a axial e, portanto, diferentes valores para $g_{x}$ e $g_{y}$. Um ajuste por simulação do espectro precisa ser feito para se obter esses parâmetros medidos com melhor precisão (ver apēndice).

Utilizando subtração espectral, feitas com auxilio de um digitalizador e do computador PDP11/45, foi possivel obter as espectros limpos do complexo predominante a $\mathrm{pH}=5.00$, è caracterizá-1o em termos espectroscópicos. As figuras 9, 10 e 11 mos tram òs dois espectros a pH=5.00 e pH=9.00, e a subtração feita da seguinte forma:

$$
\text { (espectro a } \mathrm{pH}=5.00) \text { - fator } \mathrm{x} \text { (espectro a } \mathrm{pH}=9.00 \text { ) }
$$

o fator que encontramos para a diferença nos três espectros ( de absorção ótica e de RPE nas duas temperaturas), foi o de 0.30 .

Os parâmetros espectroscōpicos medidos em $\mathrm{pH}=7.00$, estão em acordo com aqueles apresentados por Luigi sportellj. e colaboradores (Sportelli, 1977), onde vários die tripeptídeos são estudados, por RPE e absorção ótica, em um único valor de pH fixado em 7.2.

Como já foi dito no Capítulo II, na tentativa de cris talização dos espectros nos três pHs dominantes, sempre obtevese a formação de cristais de coloração azul forte, correponden te ao complexo tridentado.

O espectro de ressonância paramagnética eletrônica des te cristal foi medido e a variação angular do sinal, obtida. o espectro de RPE mostra apenas uma linha por espectro, de largura variāvel com a orientação do campo magnético, não sendo resolvida a interação hiperfina. A variação angular mostra dois ions magnéticamente não equivalentes por cela unitária. As fi - 


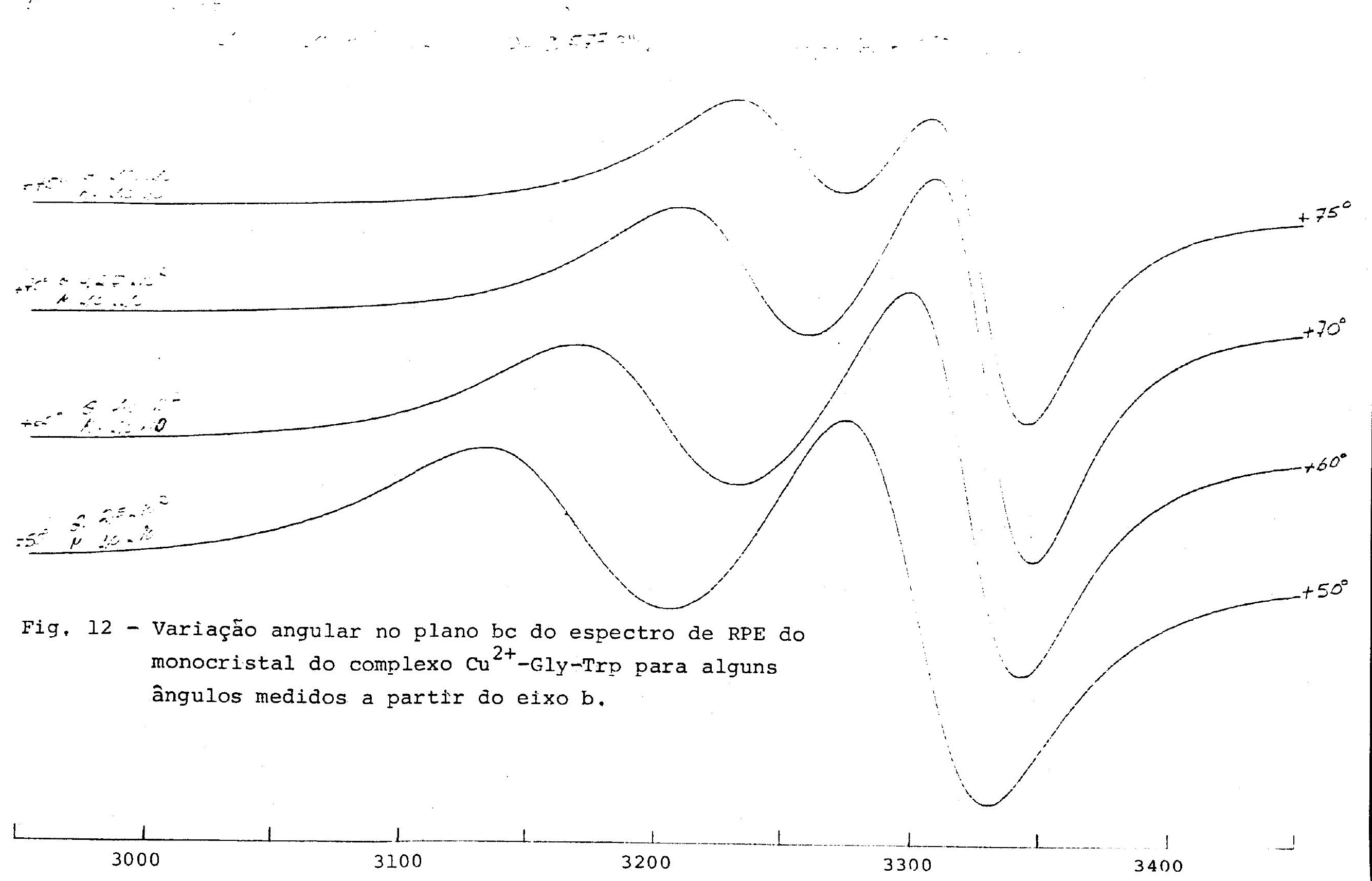




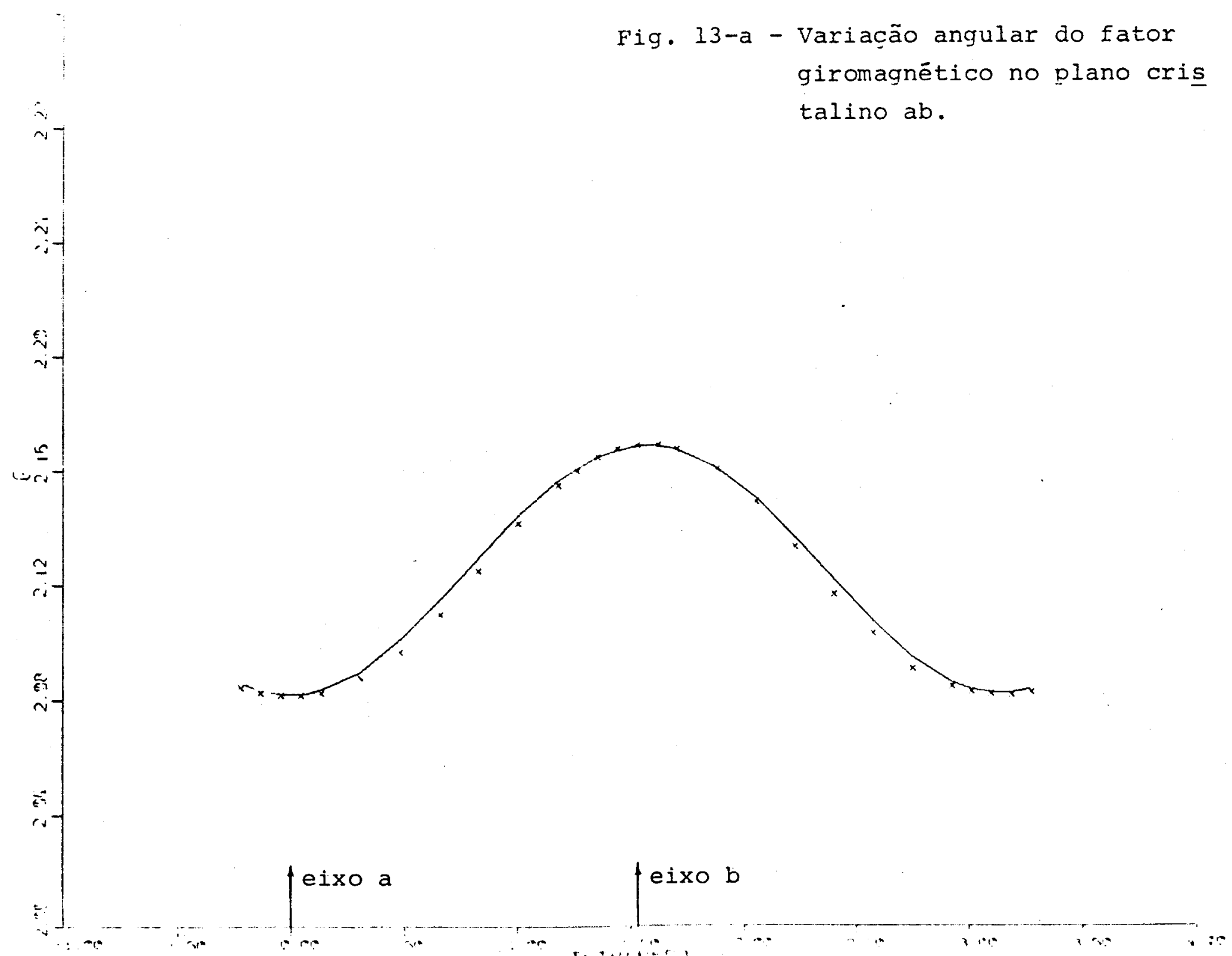




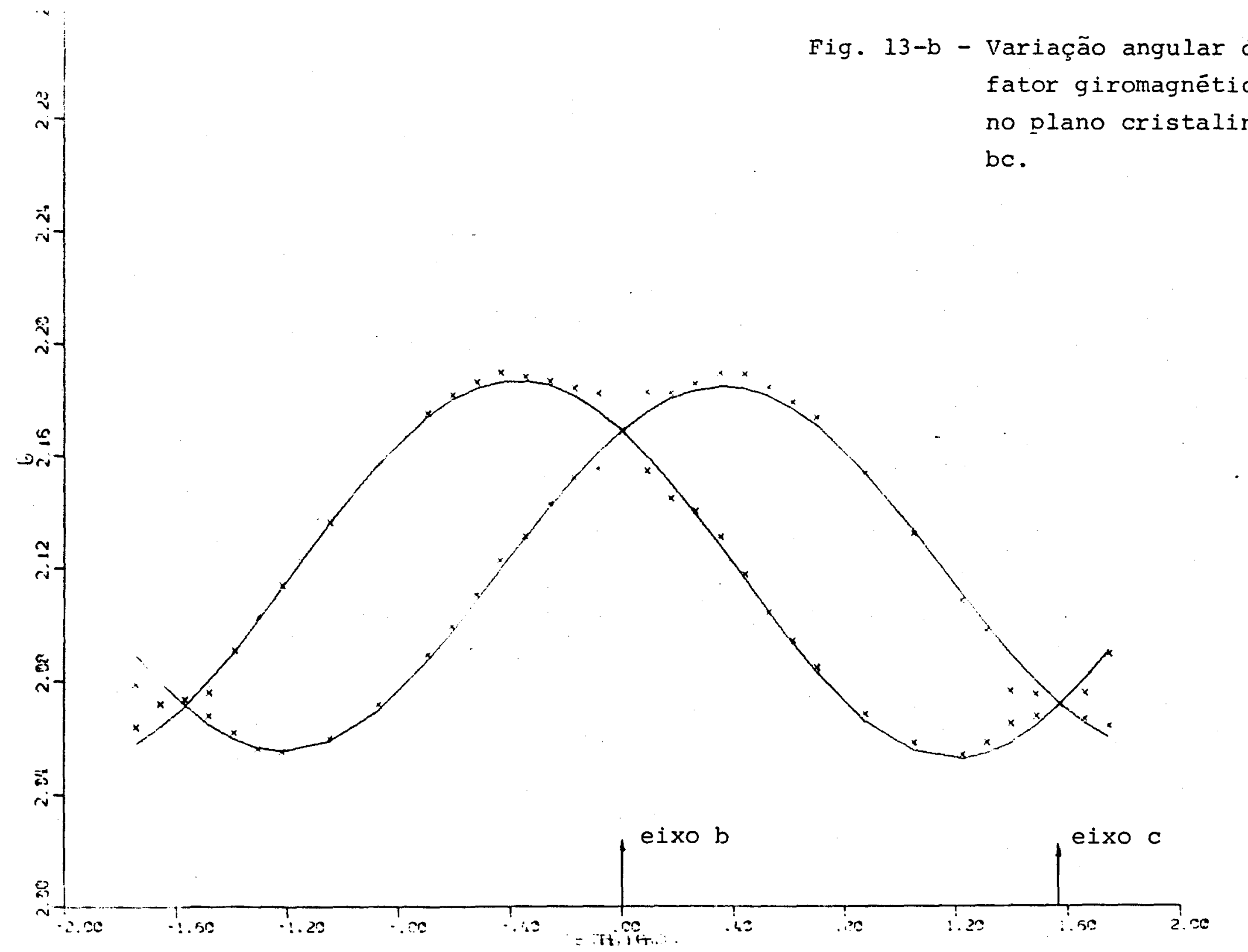


Fia. I3-c - Variação angular do fator giromagnético na plano cris talino ca.

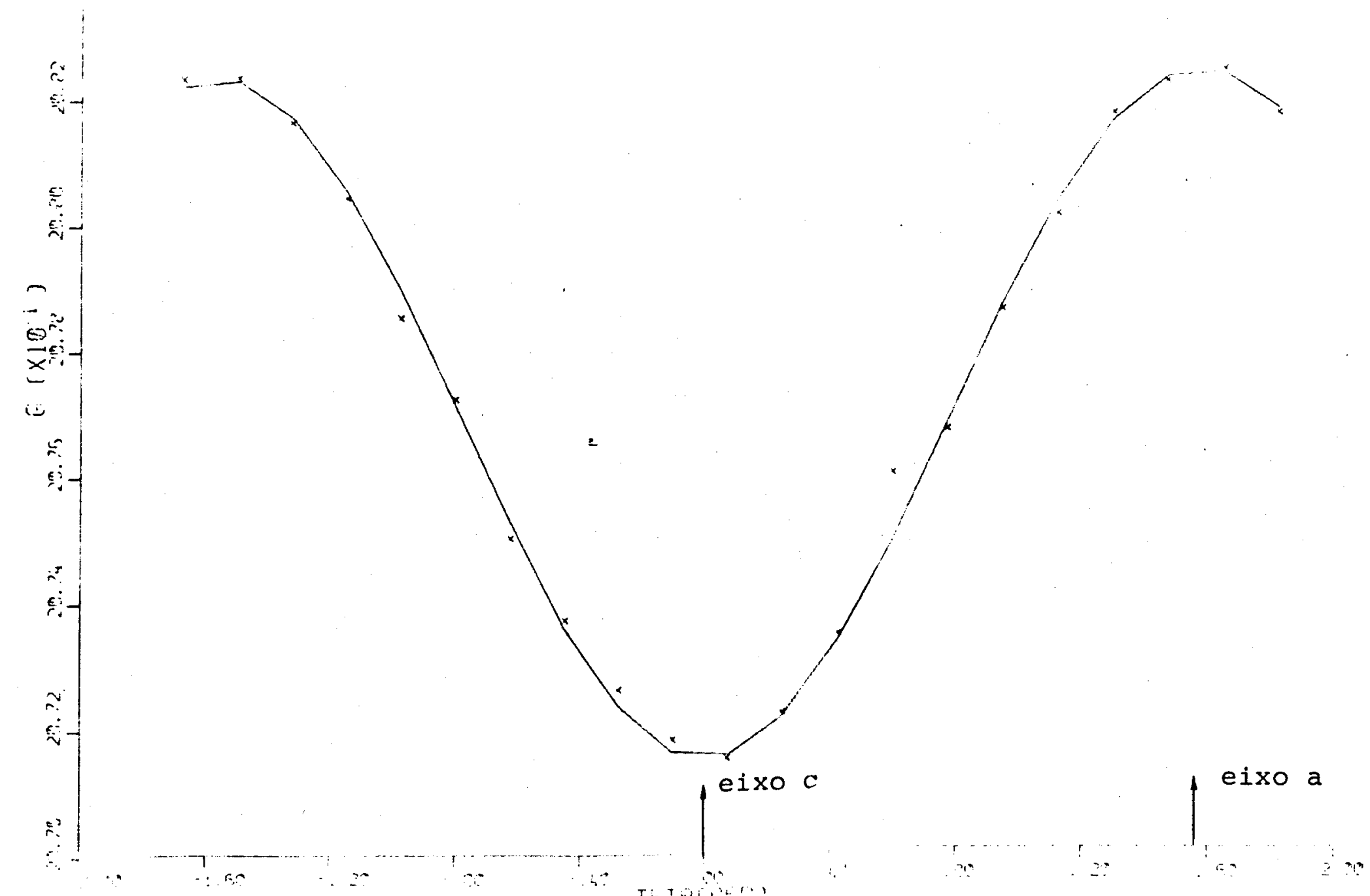


guras 12 e 13 apresentam os espectros para alguns àngulos c suas variações angulares para très planos mutuamente perpendiculares, planos-cristalinos. O tensor $\overline{\bar{g}}$ foi diagonalizado e seus auto-valores estão apresentados na Tabela VII. Os três auto-valores de $\overline{\bar{g}}$ são diferentes, mostrando uma pequena distorção rômbica na si metria. E interessante observar que o valor de $g_{0}\left(g_{0}=2.107\right)$, no cristal (obtido com o uso da expressão (2) l é diferente daquele obtido da solução a pH=9.00 (go $=2.117)$.

A estrutura cristalográfica do complexo cristalizado,

foi feita previamente por Hursthouse e colaboradores (Hursthouse, $1975)$ e identificado o quelato tridentado onde o ion de $\mathrm{Cu}^{2+}$ está ligado aos dois nitrogênios amina e peptídico, ao oxigênio car boxilato e a uma molécula de àgua. Duas moléculas de água de cris talização também foram identificadas na estrutura. Os dados cris talográficos apresentados por Hursthouse são os seguintes:

- rede cristalina ortorrômbica

- parâmetros cristalino $a=7.74(4) \AA$

$$
\begin{aligned}
& \mathrm{b}=13.78(3) \AA \\
& \mathrm{c}=14,81(3) \AA
\end{aligned}
$$

- grupo espacial $\mathrm{P} 2{ }_{1}{ }^{2}{ }^{2}{ }_{1}$ e $\mathrm{Z}=4$

O autor sugere com base nas distâncias interatômicas, as possiveis pontes de hidrogênios que estabilizam a rede. Os ions de cobre estão em uma simetria quadrado planar com peque na distorção tetraédrica. A figura 14 mostra a estrutura mole cular do complexo. As distâncias do ion de cobre aos ligantes, e os ângulos formados são os seguinte:

DISTÂNCIAS

ÂNGULOS

$\begin{array}{llllll}\mathrm{Cu} & -\mathrm{O}(2) & 1.960 & (11) \AA & \mathrm{O}(2)-\mathrm{Cu}-\mathrm{O}(4) & 92.2^{\circ} \\ \mathrm{Cu} & -\mathrm{O}(4) & 1.935 & (13) \AA & \mathrm{O}(2)-\mathrm{Cu}-\mathrm{N}(2) & 85.1^{\circ} \\ \mathrm{Cu} & -\mathrm{N}(2) & 1.879 & (13) \AA & \mathrm{N}(2)-\mathrm{Cu}-\mathrm{N}(1) & 84.2^{\circ} \\ \mathrm{Cu} & -\mathrm{N}(1) & 2.039 & (14) \AA & \mathrm{N}(1)-\mathrm{Cu}-\mathrm{O}(4) & 98.8^{\circ}\end{array}$




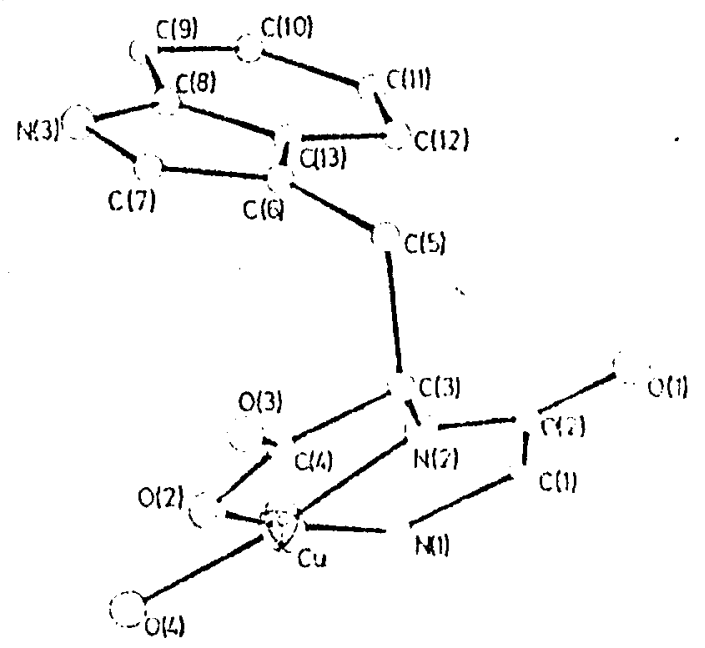

Fig. 14 - A estrutura molecular do complexo $\mathrm{Cu}^{2+}-\mathrm{Gly}-\mathrm{Tr}$ que ocorre na faixa de $\mathrm{pH}$ entre $6.50 \mathrm{e} 11.00$, determinado por cristalografia do monocristal do complexo (Hursthouse, 1975). 
Estes dados mostram a não equivalência dos átomos de nitrogênio, e também do dois àtomos de oxigênio. Um melhor refí namento da estrutura foi feita no laboratório de Cristalografia do Departamento de Física e Ciência dos Materiais de são Car los, com objetivo de melhor identificar pontes de hidrogênios, e ver se existe alguma possibilidade de esperar alguma intera ção de "exchange" entre ions, já que a resolução da interação hiperfina do espectro de RPE do cristal não é observada pelo a largamento das linhas.

o fato de existir quatro complexos por cela unitāria, como descrito pela cristalografia e, por RPE do cristal, apenas dois ions serem detectados, tem que ser explicado em face da simetria dos complexos em relação à rede cristalina. A figura 15 mostra as direções das normais aos planos que contêm os iors de $\mathrm{Cu}^{2+}$ e seus quatro ligantes em relação aos eixos cristali nos $a, b$ e $c$. E fácil de ver que se a variação angular do sinal de RPE é feita nos planos cristalinos, todos os complexos serão equivalentes nos planos ab e ac, e serão equivalentes dois a dois no plano bc, isto é, dever-se-á observar um único sinal nos planos $a b$ e ac, e dois sinais no plano bc. Além do mais, é fācil de ver, tambēm, que o tensor giromagnētico obtido atra vēs destas medidas é um tensor médio entre os complexos, dois a dois $(1-3$ e 2-4). Esta é uma razão pela qual os parāmotros medidos no cristal não estarem em acordo com aqueles obticios do complexo tridentado em, solução (ver Tabela VII). Para se obter os valores dos parâmetros moleculares calculou-se, a partir do tensor $\overline{\bar{g}}$ cristalino, os valores do tensor molecular, uma vez que as direções dos eixos moleculares são conhecidas pelos dados cristalográficos. Este cálculo é mostrado no apêndice.

o espectro de RPE do policristal, também foi obtido, e uma simulação do espectro de pó foi feita utilizando-se a hạ 


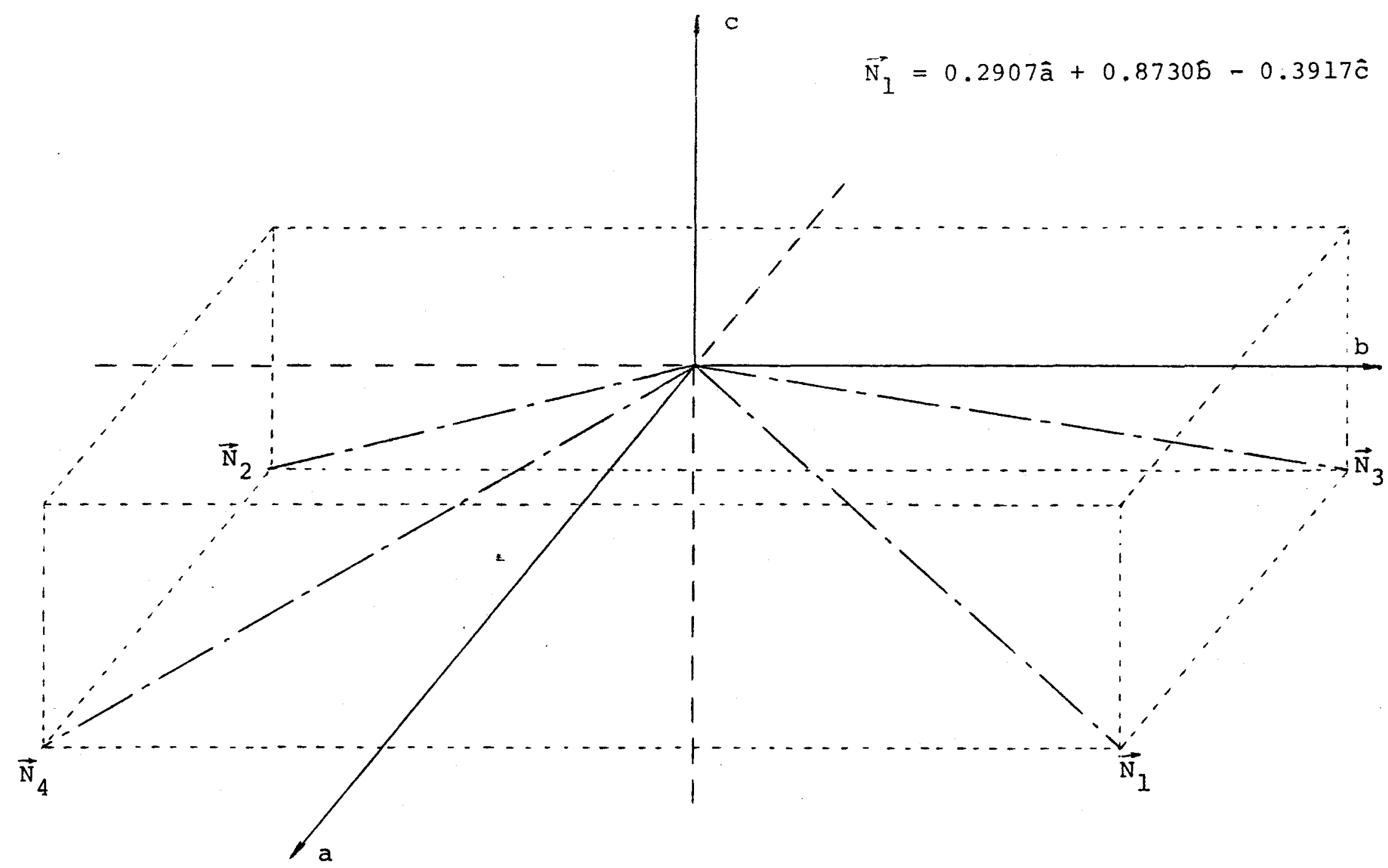

Fig. 15 - Direçōes das normais aos planos de coordenação dos complexos Cu ${ }^{2+}$-Gly-Trp determinados por cristalografia (Hursthouse, 1975 e este trabalho). 


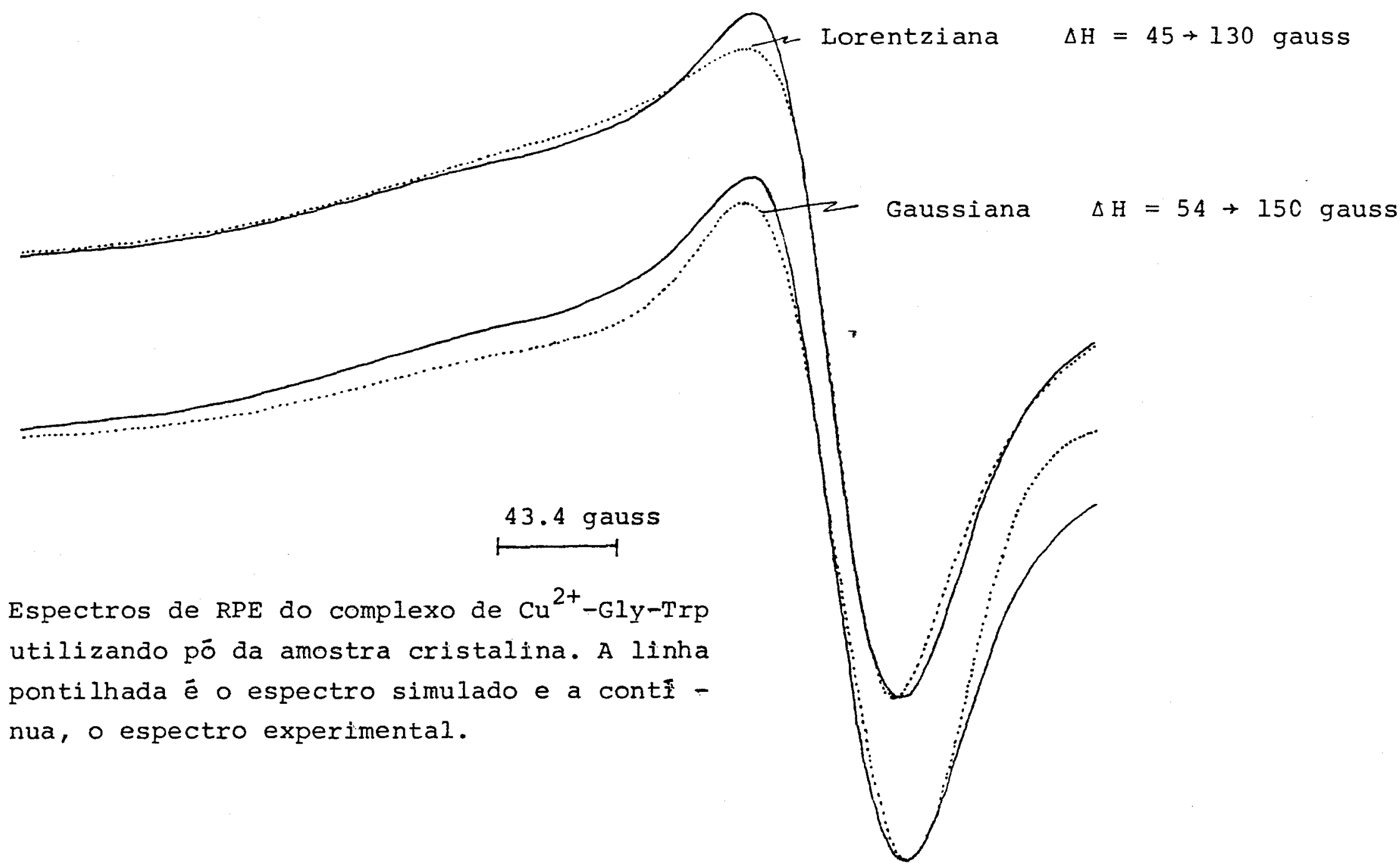

Fig. 16 - Espectros de RPE do complexo de $\mathrm{Cu}^{2+}-\mathrm{Gly}-\mathrm{Trp}$ utilizando pó da amostra cristalina. A linha pontilhada é o espectro simulado e a conti nua, o espectro experimental. 
miltoniana de spin com apenas o termo que contēm o fator giromagnético (ver apêndice). O ajuste foi feito utilizando-se uma lar gura de linha variável com a mesma variação da interação hiper fina. A simulação está mostrada na figura 16, onde as formas de linhas gaussiana e lorentziana foram utilizadas. Os parâmotros as sim ajustados, estão na Tabela VII. 
CAPITULO IV

DISCUSSÕES E CONCLUSÕES

Dos resultados obtidos nos espectros de absorção ele trônica no visivel, correspondentes às transições d-d, è possĩ vel esperar pelo menos três complexos de ions de $\mathrm{Cu}^{2+} \mathrm{com}$ o di peptideo Gly-Trp, resultados estes que, associados aos valores dos pks (empresença do ion) 'dos grupos dissociāveis do ligante, permite sugerir os complexos $\mathrm{CuL}_{2}, \mathrm{CuL}\left(\mathrm{H}_{2} \mathrm{O}\right)$ e $\mathrm{CuL}(\mathrm{OH})\left(\mathrm{H}_{2} \mathrm{O}\right)$ ell or dem crescente de $\mathrm{pH}$, sendo que o complexo de $\mathrm{pH}$ mais alto está sugerido com base em trabalhos anteriores (Kozlowski, 1977-1978 e Kaneda 1977), apresentados na literatura.

Os complexos assim sugeridos podem facilmente ser corroborados pelos espectros de RPE das soluções à temperatura am biente, onde desdobramentos do espectro devido a interações su per-hiperfinas com nūcleos de nitrogênios, mostram claramente, que o complexo $\mathrm{CuL}_{2}$ participa com um oxigênio e um nitrogênio por peptídeo. No entanto, não é possível afirmar com certeza que o nitrogènio participante seja o do grupo amina, uma vez que os pKs do grupo amina e do grupo peptídico ou amida, na preseña do ion de $\mathrm{Cu}^{2+}$ são bastante próximos (4.2 e 4.8 , respectivamente). Neste caso é necessário descobrir o nitrogênio ligante utilizando-se outras técnicas ( como absorção no infravermelho, cxista lografia desde que se obtenha cristais do complexo, etc.)

o complexo $\operatorname{CuL}\left(\mathrm{H}_{2} \mathrm{O}\right)$ mostra, em relação ao $\mathrm{CuL}_{2}$, um corrimento do espectro de absorção para comprimento de onda ine nor, evidenciando a participação do nitrogênio amida que, geralmente, liga-se ao ion mais fortemente. Pode-se observar que a dis tância Cu-N do nitrogênio amida é menor (1.879ף) que a do nitrogê nio amina $(2.039 \AA)$. Este fato vem reforçar a hipötese que no complexo $\mathrm{CuL}_{2} \circ$ ion $\mathrm{Cu}^{2+}$ está coordenado ao nitrogēnio amina. Por 
outro lado o espectro de RPE não exibe claramente o desdobrainento super-hiperfino relativo aos nitrogênios amida e amina, pela não equivalência destes ātomos ligantes. Os dados cristlogräficos fei tos por Hursthouse evidenciam claramente a estrutura deste com plexo (ver figura 14).

No espectro de RPE do complexo $\mathrm{CuL}\left(\mathrm{H}_{2} \mathrm{O}\right)$ cristalizalio, as medidas não mostram os valores dos parârnetros de RPE moleculares, mas os valores médios cristalinos, devido à simetria destes complexos na cela unitária (ver figura 15). Os parâmetros calcula dos a partir do tensor medido $\overline{\bar{g}}$ (cristalino) permitiu a obtenção dos valores corretos de $g_{\xi}, g_{n}$ e $g_{\zeta}$ (como mostrado no apéndice) sendo estes valores compatíveis com o espectro obtido da amostra em solução em pH ao redor de 9.00 .

A simulação do espectro do policristal mostra claramente que a interação hiperfina è responsável pela variação na largu ra de linha com o campo magnético, e que a forma de linha do si nal é essencialmente lorentziana.

Observando-se a estrutura cristalográfica, não fica cla ra a existência de algum mecanismo de "exchange" para o alargamen to da linha de RPE que esconde a interação hiperfina, alëm do que os ions de $\mathrm{Cu}^{2+}$ mais próximos estão a $7.20 \AA$ de distāncia. Desta forma uma interação dipolar magnética é mais plausivel como necanismo de alargamento de linha.

Com relação ao complexo obtido a $\mathrm{pH}=13.20$, os parâme tros de RPE mostram uma redução apreciāvel na componente $A_{z}$ com uma evidente distorção e quebra da simetria axial. A diferença $\left|g_{x}-g_{y}\right|$ é uma medida desta distorção que está em acordo con aqueles apresentados na Tabela VI. Neste caso, esta distorção pode ser explicada pela saida do proton do nitrogènio do resíduo de triptofano, mudando as distâncias $\mathrm{N}-\mathrm{C}$ do anel, e produzindo um cambio estrutural que, ou arranca o oxigênio da carboxila, ou dis 
torce a ligação para uma simetria tetraêdrica distorcida, onde funções $\mathrm{p}$ e $\mathrm{s}$ do próprio ion de $\mathrm{Cu}^{2+}$ misturam com os orbitais do ligante reduzindo o valor de Az (Brill, 1977). Por outro 1ado, esta mistura é suficientemente pequena para não mudar a absortividade da banda de absorção ọtica. Outra evidência da ocorrência desta distorção é vista pela resolução do desdobramento da linha de campo alto do espectro à temperatura ambiente, mostrando que os dois nitrogènios ficam equivalentes e o valor do parāmetro de interação cresce de um gauss em relação ao complexo em pH=5.00, devido a uma maior deslocalização eletrônica sobre estes nitrogê nios. Tentativa de crescimento de cristais deste complexo cstá sendo levada a efeito para clarificar este ponto que é bastante importante para entendimento dos complexos cúpricos das proteínas azuis.

Como conclusão deste trabalho, pode-se dizer que:

1. para determinação das diferentes espēcies de complexos de $\mathrm{Cu}^{2+}$ e o dipeptídeo Glicil-triptofano, é importante associar à absorção ótica comumente usada na química de coordenaçä́n, à técnica de ressonāncia paramagnētica eletrōnica de uma llia neira sistemātica, inclusive utilizando subtração espectral;

2, três diferentes espécies do complexo são caracterizados espectroscópicamente e para dois deles são discutidas suas co ordenações $(\mathrm{pH}=5.00$ e $\mathrm{pH}=13.20)$;

3. o complexo a pH 13.20 confirma a importância do resíduo lateral pesado do dipeptídeo na simetria do complexo, dincio paràmetros espectrais de RPE parecidos com os apresentados pelas proteinas azuis. 


\section{APENDICE}

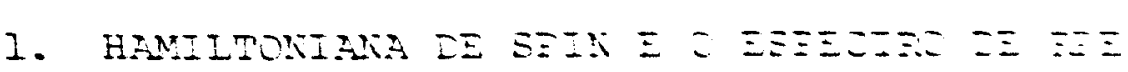

A hamiltoniana de spin para o ion $\mathrm{Cu}^{2+}$ será aqui apresentada de maneira suscinta com o único objetivo de tornar claro o significado dos parâmetros de RPE medidos e apresentados ao lon go dos capitulos anteriores.

Pelo fato de o ion $\mathrm{Cu}^{2+}$ conter nove eletrons na sua ú tima camada $3 d$, ele pode ser considerado um estado de buraco em uma camada $3 d^{10}$ cheia e, portanto, ser descrito em termos do esta do $3 \mathrm{~d}^{1} \mathrm{com}$ os niveis de energia invertidos. Este fato permite, tam bém, descrever os espectros de RPE como aquele produzido por um eletron 3d desemparelhado com $s=\frac{1}{2}$.

Assim, pode-se escrever a hamiltoniana efetiva de spin da seguinte forma:

$$
H^{\prime}=\beta \overrightarrow{\mathrm{H}} \cdot \overrightarrow{\bar{g}} \cdot \vec{S}+\vec{I} \cdot \overline{\bar{A}} \cdot \vec{S}+\sum_{i=1}^{n} \vec{I}_{n}^{i} \cdot \overline{\bar{A}}_{i} \cdot \vec{S}
$$

onde os outros termos da hamiltoniana, ou não interessam ni anālise aqui apresentada, ou apenas contribuem no alargamento das linhas do espectro.

o primeiro termo descreve a interação zeeman e efoito spin-örbita combinados no tensor $\overline{\bar{g}}$ (interação Zeeman efetiva). 0 segundo descreve a interação hiperfina do spin eletrônico con o spin nuclear do ion de $\mathrm{Cu}^{2+}(I=3 / 2)$, e o terceiro descreve a interação super-hiperfina do spin eletrōnico com os spins nuciea res dos núcleos vizinhos (em especial nitrogênios), devido ì des localização eletrônica sobre os átomos ligantes.

\section{INTERAÇÃO ZEEMAN EFETIVA}

O termos zeeman efetivo é descrito através do tensor $\overline{\bar{g}}$ que contem nele a contribuição devida à interação spin-órbita,en 
volvendo os estados-misturas entre os níveis 3 desdobradus ine campo cristalino.

Ele é escrito pela expressão abaixo:

$$
H_{z}=\beta \vec{H} \cdot \overline{\bar{g}} \cdot \overrightarrow{\mathrm{s}}
$$

como o produto interno do vetor $H . \overline{\bar{g}}$ e o operador vetorial $S$.

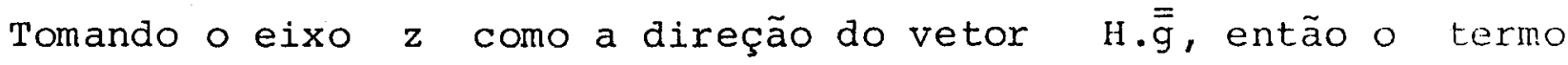
de Zeeman será:

$$
\mathcal{H}_{z}=\beta|\overrightarrow{\mathrm{H}} \cdot \overline{\bar{g}}| \mathrm{S}_{\mathrm{z}}
$$

e as energias serão dadas por:

$$
\varepsilon=\beta|\overrightarrow{\mathrm{H}} \cdot \overline{\bar{g}}| \mathrm{M}_{\mathrm{S}} \quad \text { com } \mathrm{M}_{\mathrm{S}}= \pm I / 2
$$

A transição produzida pela técnica de RPE muda o ele tron da energia E_ para a energia $E_{+}$sendo, portanto, necessá rio um foton com energia dada pela diferença dos dois niveis e igual a :

$$
\eta \nu=B|\overrightarrow{\mathrm{H}} \cdot \overline{\bar{g}}|=E_{+}-E_{-}
$$

o tensor $\bar{g}$ è um tensor de segunda ordem, simétrico, e é conveniente escrevê-10 em termos dos três eixos principais e de seus auto-valores.

Supondo que estes eixos são $\xi,$, e que os cossenos diretores do campo $\vec{H}$ em relação a estes eixos são $1, m$ e n. Pode-se escrever, então que:

$$
\overrightarrow{\mathrm{H}} \cdot \overline{\bar{g}}=\left(g_{\xi} l, g \mathrm{~m}, \mathrm{~g} \mathrm{n}\right) \mathrm{HO}
$$

e as energias dadas, portanto, por:

$$
\begin{gathered}
E=g B \text { HoMs } \quad, M s= \pm l / 2 \\
g^{2}=g_{\xi}^{2} l^{2}+g^{2} m^{2}+g^{2} n^{2}
\end{gathered}
$$

Pode-se observar que se o tensor $\overline{\bar{g}}$ for isotrópico, isto $\bar{e}, g_{\xi}=g=g=g_{0}$ então $g^{2}=g_{0}^{2}$.

Em caso de simetria axial $g_{\xi}=g=g$ e $g=g$ e $g^{2}=g^{2}\left(1-n^{2}\right)+g^{2} n^{2}$ onde $n=\cos \theta$ e $\theta$ é o ângulo entre a direção do campo magnético e o eixo axial de simetria.

Num exemplo prático, não se sabe a priori as dirocoes 
principais do tensor $\overline{\bar{g}}$, sendo estas uma das informaçōes qua se de seja obter. O que se faz, então, è medir o campo Ho de ressonân cia em função do ângulo para três planos mutuamente perpendiculares, cujas interações formam o sistema de referencia do laboratōrio $a, b, c$. Geralmente procura-se tomar $a, b, c$ como as direções cris talinas da amostra, no caso de um monocristal.

Neste caso o valor $\overline{\bar{g}}$ em uma direção qualquer do carmpo $\overrightarrow{\mathrm{I}}$ no plano ab, por exemplo, serā:

(9) $\quad g^{2}=g_{a a}^{2} \cos ^{2} \theta+g_{b b}^{2} \operatorname{sen}^{2} \theta+2 g_{a b}^{2} \operatorname{sen} \theta \cos \theta$

onde $\theta$ é o ângulo que $\overrightarrow{\mathrm{H}}$ faz com o eixo a. As medidas nos trés planos permitem a construção do tensor $\overline{\bar{g}}$ no sistema $a, b, c$ que diagonalizado fornece os auto- valores $g_{\xi}, g$ e $g$ e as dire ções principais correspondentes.

\section{INTERAÇÃO HIPERFINA}

A interação hiperfina envolve a interação magnētica do spin eletrônico com spin nuclear do próprio nucleo do ion. Esta interação é descrita pelo termo I. $\overline{\bar{A}} . S$ e, incluindo este tormo na hamiltoniana zeeman tem-se:

$$
=\beta \overrightarrow{\mathrm{H}} \cdot \overline{\bar{g}} \cdot \overrightarrow{\mathrm{S}}+\overrightarrow{\mathrm{I}} \cdot \overline{\overline{\mathrm{A}}} \cdot \overrightarrow{\mathrm{S}}
$$

Consideranao os casos em que o termo de $\mathrm{Z}$ eeman $\overrightarrow{\mathrm{e}}$ muito maior que o termo hiperfino, e usando termos até primeira ordem, tem-se que:

$$
H=\beta|\overrightarrow{\mathrm{H}} \cdot \overline{\bar{g}}| \mathrm{S}_{\mathrm{z}}+\frac{\overrightarrow{\mathrm{H}} \cdot \overline{\bar{g}} \cdot \overrightarrow{\overline{\mathrm{A}}} \cdot \overrightarrow{\mathrm{I}}}{|\overrightarrow{\mathrm{H}} \cdot \overline{\bar{g}}|} \cdot \mathrm{S}_{\mathrm{z}}
$$

Escolhendo um sistema de coordenadas com $z^{\prime}$ na direção $\overrightarrow{\mathrm{H}} \cdot \overline{\bar{g}} \cdot \overline{\overline{\mathrm{A}}}$, pode-se escrever que:

$$
f_{f}=g B \mathrm{H}_{0} \mathrm{~S}_{z}+\frac{|\overrightarrow{\mathrm{H}} \cdot \overline{\bar{g}} \cdot \overline{\overline{\mathrm{A}}}|}{\mathrm{gH}_{\mathrm{O}}} \mathrm{s}_{z^{I} z^{\prime}}
$$

As energias são expressas até primeira ordem por:

$$
E=g B H_{O} M_{s}+A M_{s} M_{i}
$$


onde g é dado pela equação (8) e A é dado por:

(14) $\quad A=\frac{1}{g_{0}}|\vec{H} \cdot \overline{\bar{g}} \cdot \overline{\bar{A}}|$

Se os sistemas de eixos principais de $\overline{\bar{g}}$ e $\overline{\bar{A}}$ são (); mesmos, como ocorre nos casos aqui apresentados, então:

$$
A=\frac{1}{g}\left(A_{\xi}^{2} g_{\xi}^{2} 1^{2}+A_{n}^{2} g_{n}^{2} m^{2}+A_{\zeta}^{2} g_{\zeta}^{2} n^{2}\right)^{1 / 2}
$$

As transições eletrōnicas vão ocorrer obedecendo ìs regras de seleção $\Delta M_{S}= \pm 1$ e $\Delta M_{i}=0$ e as energias do fotrns se rão dadas por:

(16) $\quad \mathrm{h} \nu=g B \mathrm{H}_{0}+\mathrm{AM} \mathrm{M}_{i}$

e os valores dos campos ressonantes $\mathrm{H}_{\mathrm{O}}$ dados por:

$$
\mathrm{H}_{\mathrm{O}}=\frac{\mathrm{h} \nu}{\mathrm{g} \beta}-\frac{\mathrm{A} \mathrm{M}_{i}}{\mathrm{~g} B}
$$

o espectro consistirá, portanto, de $2 I+1$ linhas iqual mente espaçadas (em primeira ordem). com o espaçamento dado nelo valor de A medido em unidades de campo mannético. Para o ion de $\mathrm{Cu}^{2+}, \mathrm{I}=3 / 2$ e o espectro consistirá de quatro linhas.

Se o sistema apresenta simetria axial, então:

$$
A_{\xi}=A_{n}=A_{\perp} \text { e } A_{\zeta}=A_{/ /}
$$

e o valor de A será:

$$
A=\frac{1}{g} \cdot\left(A_{/ /}^{2} g_{/ /}^{2} \cos ^{2} \theta+A_{L}^{2} g_{\perp}^{2} \operatorname{sen}^{2} \theta\right)^{1 / 2}
$$

onde é o ângulo que $\overrightarrow{\mathrm{H}}$ faz com o eixo axial. Para a simetria cúbica ou esférica, então os três valores $A_{\xi}, A_{n}$ e $A_{\zeta}$ serão iguais e $A=A_{0}$.

Se for utilizado termos até segunda ordem, no caso de simetria axial, a expressão para os valores dos campos ressonan tes é dada por:

$$
\text { (18) } \begin{aligned}
H & =\frac{h \nu}{g B}-\frac{A M_{i}}{g B}-\frac{A \perp^{2}\left(A_{U}^{2}+A^{2}\right)}{4 h \nu g B A^{2}}\left[I(I+1)-M_{i}\right]^{2} \\
& -\frac{\left(A_{/ 1}^{2}-A^{2}\right)_{/ \mu}^{2} g_{\perp}^{2} \operatorname{sen}^{2} \theta \cos ^{2} \theta M_{i}^{2}}{2 h v g^{5} B A^{2}}
\end{aligned}
$$


No caso do ion de $\mathrm{Cu}^{2+}$ os termos em $\mathrm{M}_{1}^{2}$ poden repre sentar correções significativas devido à grande anlsotropl.: dos tensores $\overline{\bar{g}}$ e $\overline{\bar{A}}$.

\section{4. interação super-hiterfina}

A interação super-hiperfina é anāloga à lnterạia lị̂ -fina, já que ela descreve a interação do spin eletrinico cos spins nucleares dos núcleos vizinhos. Esta interação e, goilikute, bem menor que a interação hiperfina e o seu efeito é a.: lo brar as linhas hiperfinas em multipletes que vão depender (l) nú mero de ions com spins nucleares e suas simetrias e, obviaincnte, do valor dos spins nucleares. Por exemplo, se houver um unico nitrogênio $\left(I_{N}=1\right)$ coordenado com o ion $\mathrm{Cu}^{2+}$, é esperado que as qua tro linhas do espectro de RPE se desdobrem, cada uma, em tripletes correspondentes aos três valores de ${ }^{M_{I_{N}}}$. A separação das linhas dos tripletes medem o valor do tensor $\overline{\bar{A}}_{i}$ para a direção dada do campo magnético. Este tensor é, geralmente, anisotrópico. Entre tanto, o fato de seu valor ser, em alguns casos, menor que as lar guras de linhas do espectro, faz com que este desdobramento não seja observado, a não ser em algumas direções onde o valor do ten sor seja maior que a largura de linha.

No caso de existir mais de um nücleo na coordenaçüo do ion, que possua spin nuclear, ou considera-se cada núcleo indivi dualmente como um termo da interação, e o resultado será a superposição dos desdobramentos de cada um deles, ou se considera grupos de núcleos que possam ser equivalentes, e neste caso o spin nuclear total será a superposição deles, dando desdobranentos cor respondentes ao spin total e as intensidades das linhas serão proporcionais às suas frequências estatísticas. Por exemplo, seja a existência de, dois nitrogênios equivalentes. Neste caso, o ter- 
mo super-hiperfino será:

(19) $H_{\text {shf }}=\sum_{i=1}^{2} \vec{I}_{N}^{i} \cdot \overrightarrow{\bar{A}}_{i} \cdot \vec{S}=\vec{I}_{I} \cdot \overline{\bar{A}}_{1} \cdot \vec{S}+\vec{I}_{2} \cdot \vec{A}_{2} \cdot \vec{S}$

Sendo eles equivalentes, $\overline{\overline{\mathrm{A}}}_{1}=\overline{\overline{\bar{A}}}_{2}=\overline{\overline{\bar{A}}}_{\mathrm{N}}$

(20) $H_{\mathrm{Shf}}=\overrightarrow{\mathrm{I}} \cdot \overline{\bar{A}}_{\mathrm{N}} \cdot \overrightarrow{\mathrm{S}}$

$\operatorname{com} \vec{I}_{=} \vec{I}_{1}+\vec{I}_{2}$

Como o valor de $I_{1}=I_{2}=1$, então, $I=2$ e o número de linhas do multiplete será cinco, com os pesos de $1: 2: 3: 2: 1$, para suas intensidades.

Tudo que foi resumido até agora vale para espectros obtidos de uma amostra cristalina. Se a amostra estiver em solução, então os movimentos de rotação dos complexos farão uma mé dia angular na hamiltoniana de spin, e somente os valores nédios dos parâmetros de interação $\left(\overline{\bar{g}}, \overline{\bar{A}}\right.$ e $\left.\overline{\bar{A}}_{N}\right)$ serão observados;. Os parâmetros $g_{O}, A_{O}$ e $a_{N}$ serão dados pelas expressões:

$$
\begin{aligned}
& g_{0}=\frac{1}{3}\left(g_{\xi}+g_{n}+g_{\zeta}\right) \\
& A_{0}=\frac{1}{3}\left(A_{\zeta}+A_{n}+A_{\zeta}\right) \\
& a_{N}=\frac{1}{3}\left(A_{\zeta}^{N}+A_{\eta}^{N}+A_{\zeta}^{N}\right)
\end{aligned}
$$

como usado no Capítulo III.

A hamiltoniana de spin resumidamente apresentada aqui, está bem discutida e apresentada em vários textos como o de Abragam e Bleaney (1970) e o de G.E.Pake (1973).

5. CÁlculo do tensor $\overline{\bar{g}}$ MOLEcular a partir do TENSOR $\overline{\bar{g}}$ CRISTALINO

Devido ao fato de que o complexo $\mathrm{Cu}^{2+}-\mathrm{Gly}-\mathrm{Trp}$ tridentado, que foi cristalizado, ocorrer em quatro posições da célula unitāria, com operações de simetria do cristal que leva um no ou tro, as medidas de RPE no cristal não permitem a obtenção direta do tensor $\overline{\bar{g}}$ molecular do complexo, e sim um tensor $\overline{\bar{g}}$ médio, que guarda a simetria cristalina (ver figura 15). No entanto, se são 


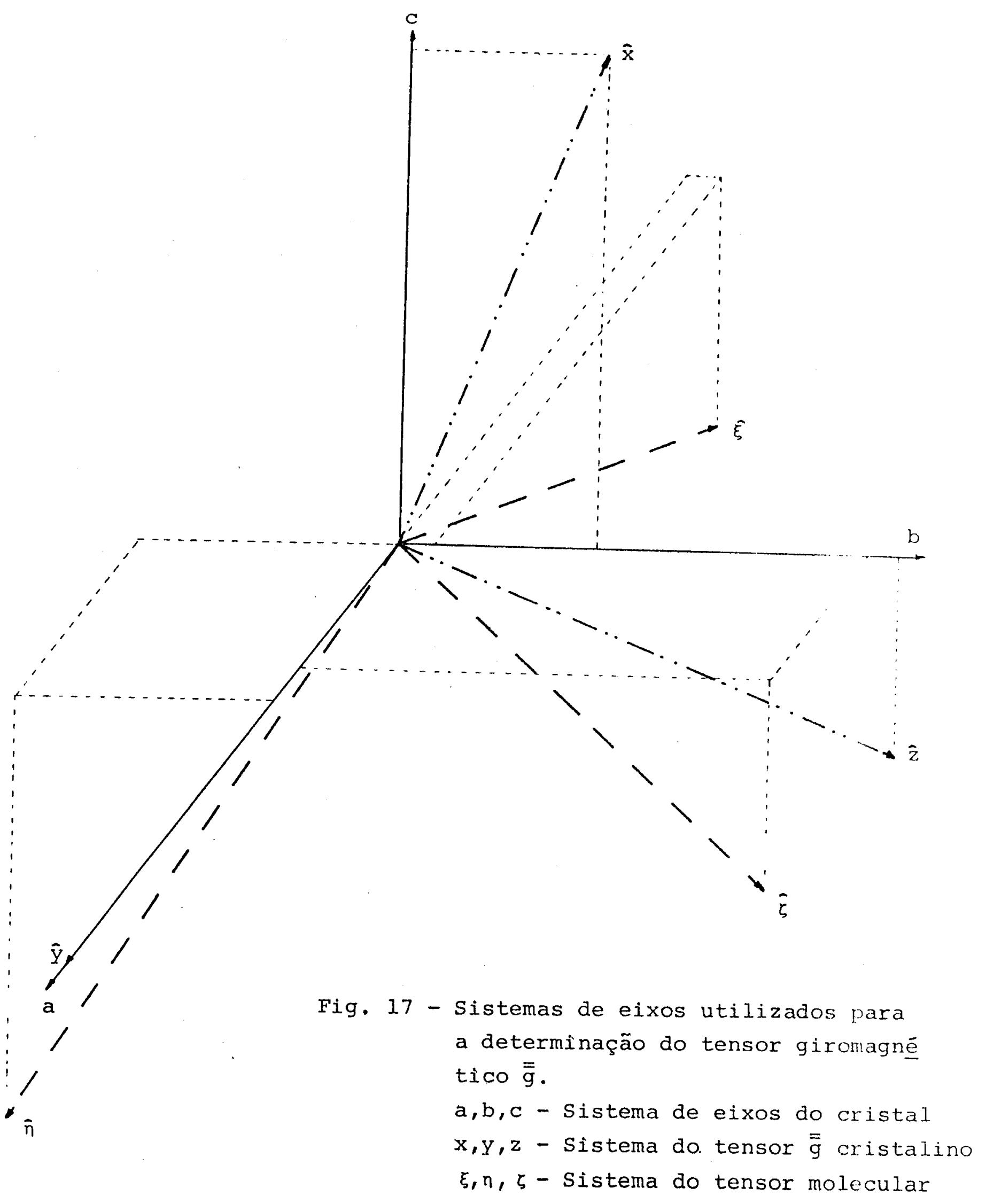


conhecidos, pelos dados cristalográficos, os eixos moleculares, $\xi, \eta$ e $\zeta$, é possivel calcular os valores de $g_{\xi}, g_{\eta} \circ g_{\zeta} a$ partir dos valores do tensor $\overline{\bar{g}}$ cristalino.

Sejam a, b e c os eixos cristalinos e $x, y$ e z al dire ções principais obtidas das medidas e anālise dos espectros de RPE da amostra (ver figura 17). Seja $\xi, n$ e $\zeta$ o sistema de ei xos moleculares de uma das moléculas que ocorrem na célula unitạ ria. O eixo $\zeta$ é a normal ao plano de coordenação e $\xi$ e $\eta$ apontam respectivamente nas" direções $0(2)-\mathrm{N}(1)$ e $0(4)-\mathrm{N}(2)$, no pla no de coordenação (ver figura 14). Aqui, se supõe que o estado fundamental do eletron desemparelhado é descrito pela função:

$$
\mathrm{d}^{2}-\mathrm{y}^{2}
$$

Pelos dados de RPE e cristalográficos, é possivel es crever que:

$$
\begin{aligned}
& \hat{x}=0.0000 \hat{a}+0.3719 \hat{b}+0.9283 \hat{c} \\
& \hat{y}=1.0000 \hat{a}+0.0000 \hat{b}+0.0000 \hat{c} \\
& \hat{z}=0.0000 \hat{a}+0.9283 \hat{b}-0.3719 \hat{c} \\
& \hat{\xi}=-0.8814 \hat{a}+0.0667 \hat{b}-0.4646 \hat{c} \\
& \hat{\eta}=0.3711 \hat{a}-0.4838 \hat{b}-0.79 .26 \hat{c} \\
& \hat{\zeta}=0.2907 \hat{a}+0.8730 \hat{b}-0.3917 \hat{c}
\end{aligned}
$$

A matriz de transformação que leva o sistema $\xi, \eta, \zeta$ em $a, b, c$ é dada por

$$
\overline{\overline{\mathrm{T}}}=\left(\begin{array}{ccc}
-0.8814 & 0.0667 & -0.4646 \\
0.3711 & -0.4838 & -0.7926 \\
0.2907 & 0.3730 & -0.3917
\end{array}\right)
$$

Usando a matriz transposta para escrever à, $b$ e $\hat{c}$ em termos de $\xi, \eta, \zeta$ pode - se escrever por simples substituição $\hat{x}, \hat{y}$ e $\hat{z}$ em termos de $\xi, n$ e $\zeta$, isto é:

$$
\begin{aligned}
& \hat{x}=-0.4065 \hat{\xi}-0.9157 \hat{n}-0.0389 \xi \\
& \hat{y}=-0.8814 \hat{\xi}+0.3711 \hat{n}+0.2907 \hat{\zeta} \\
& \hat{z}=0.2347 \hat{\xi}-0.1543 \hat{n}+0.9561 \xi
\end{aligned}
$$


Se $\overline{\bar{g}}$ está escrito em relação aos eixos principais mole culares $\xi, \eta, \zeta$, então é possível obter os valores de ${ }^{\prime}, g_{y}$ e $g_{z}$ em termos de $g_{\xi}, g_{n}$ e $g_{\zeta}$ como segue:

$$
\hat{x} \cdot \overline{\bar{g}} \cdot \hat{x}=g_{x}, \quad \bar{y} \cdot \overline{\bar{g}} \cdot \hat{y}=g_{y} \text { e } \hat{z} \cdot \overline{\bar{g}} \cdot \hat{z}=g_{z}
$$

$\operatorname{com} \quad\left(\begin{array}{ccc}g_{\xi} & 0 & 0 \\ 0 & g_{n} & 0 \\ 0 & 0 & g_{\zeta}\end{array}\right)$

Numericamente, obtēm-se o sistema de equações:

$$
\begin{aligned}
& 0.1652 \mathrm{~g}_{\xi}+0.8385 \mathrm{~g}_{n}+0.0015 \mathrm{~g}_{\zeta}=2.054 \\
& 0.7769 \mathrm{~g}_{\xi}+0.1377 \mathrm{~g}_{n}+0.0845 \mathrm{~g}_{\zeta}=2.082 \\
& 0.0551 \mathrm{~g}_{\xi}+0.0238 \mathrm{~g}_{n}+0.9141 \mathrm{~g}_{\zeta}=2.185
\end{aligned}
$$

Resolvendo o sistema pelo método de cramer obtēn-se, fi nalmente, os valores:

$$
g_{\xi}=2.078, g_{n}=2.036 \text { e } g_{\zeta}=2.212
$$

6. SIMULAÇÃO DO ESPECTRO DE PO

A simulação do espectro de pó é feita a partir do cálculo que consiste em determinar a intensidade da derivada da absorção paramagnētica em função do campo magnētico externo H atravēs da seguinte expressão:

$$
\begin{aligned}
I(H) & =\int S^{\prime}\left(H-H_{0}\right) \\
& s(H) d H \\
& =(2 I+I)^{-1} \int_{0}^{\pi / 2} S^{\prime}\left(H-H_{0}\right) g_{I}^{2} \operatorname{sen} \theta d \theta
\end{aligned}
$$

onde $g_{1}=g_{\perp}^{2}\left[\left(\frac{g_{l l}}{g}\right)^{2}+1\right] / 8$

I é o spin nuclear do ion paramagnético, $g$ e $H_{0}$ são da dos pelas equações (8) e (18) para simetria axial.

S' $\left(\mathrm{H}-\mathrm{H}_{\mathrm{O}}\right)$ é a derivada da forma de linha normalizada ( Lorentziana ou Gaussiana). No caso aqui apresentado, o valor de - Ho é simplesmente calculado pela equação (8) onde:

$$
g=\left(g_{/ /}^{2} \cos ^{2} \theta+g_{\perp}^{2} \operatorname{sen}^{2} \theta\right)^{1 / 2}
$$

utilizando largura de linha intrínseca variável com a mesma de - 
pendència angular da interação huperfina em sistema axial. 


\section{REFERENCIAS BIBLIOGRAFICAS}

ABRAGAM,A., BLEANEY, B. : "Electron Paramagnetic Resonimes of Ions", Clarendon Press, Oxford, 1970.

BRILL,A.S.; BRYCE, G.F. : J.Chen. Ihys., 48, 1398 (1968)

+ BRILL, A.S.: "Transition Metals in Biochemistry" - SpringerVerlag, NY (1977).

BRIVING,C.; DEINUN, J.: FEBS Letters, 51, 43 (1975)

FINAZZI-AGRO,A.; GIOVAGNOLI,C.; AVIGLIANO,L.; ROTILIO, (:. ;

MONDOVI, B. : J. Biochem., 34, 20 (1973).

FREEMAN, H.C.: "Inorganic Biochemistry", Chap.4, Eichhorn,G.I. (ed.), Elsevier, Amsterdam (1973).

GRAY, H.B.; MC MILLIN, D.R., ROSENBERG,R.C.: Proc. Nat1. Acad. Sci. V.S., 71, 4760 (1974).

HARTZELL, C.R., GURD,F.R.N.: J.Biol.Chem. 244, 3038 (1968). HURSTHOUSE, M.B . , JAYAWEERA, S.A.A . ; MILBURN, H .,QUICK, A. : J . C.S . Dalton, 2569 (1975).

JEZOWSKA - TRZEBIATOWSKA, B.; KOZLOWSKI, H.: Chem.Phys.Lctters 42, 246 (1976) Erratum, 46, 398(1977)

.KATOH,S.; TAKAMIYA,A. : Biochemistry, 55, 378(1964)

KOzLOWSKI, H.: Chem. Phys. Letters, 46, 519 (1977)

KOZLOWSKI,H .; JEZOWSKA - TRZEBIATOWSKÁ, B.: J.MOl. Structure, $\underline{45}, 159(1978)$

KRONECK, P.: J.Am. Chem. Soc., 97, 3839 (1975)

MALMSTROM, B.G., REINHAMMAR, B.; VANGARD,T.: Biochim.Biophys . Acta, 205, $48(1970)$

MARIA, H.J.: Nature (Iondon), 209, 1023 (1966)

MARKLEY, J.L.; ULRICH, E.L.; BERG, S.P.; KROGMANN, D.W.:BiOChEM istry, 14, 4428 (1975).

MISKOWSKI,V; TANG, S.P.W.; SPIRO, T.G.; SHAPIRO,E.; MOSS, T.H.: Biochemistry, 14, 1244(1975)

MIYOSHI,K.; YSHIZU, K.; SUGIURA, Y.:Chem. Letters, (7) 669 (1976) 
MORPURGO,L.; FINAZZI-AGRO,A; ROTILIO, G. ; MONDAVI, B . : Bi ochim.

Biophys. Acta, 271, 292(1972)

PAKE,G.E.; ESTLE, T.L.: "The physical principles of Electron Paramagnetic. Resonance", 2nd ed., W.A.Benjamin, Inc. (1973).

PEISACH,J.; LEVINE,W.G.; BLUMBERG, W.E.: J.Biol. Chem. 242 , 2847 (1967)

SIIMAN,O.; YOUNG, N.M.; CAREY, P.R.:J.Am.Chem. SOC., 98, 744 (1976) .

SOLOMON, E.I.; HARE,J.W.; GRAY,H.B.: PrOC. Natl. Acad.Sci.V.S. 73, $1389(1976)$.

SPORTELLI,L.; NEUBACHER,H .;LOHMANN, W.: Biophys.Struct.Mech . , $\underline{3}, 317(1977)$.

STIGBRAND, T.; SJOHOLM, I.: Biochim., Biophys. Acta, 263,244(1972) SUGIURA, Y.; TANAKA,H.: Chem.Pharm.Bul1., 18, 368 (1970). SUGIURA, Y.; TANAKA,H.: Mol.Pharmacol . , 8, 249(1972). SUGIURA, Y.; HIRAYAMA, Y.; TANAKA, H.; YSHIZU, K.: J.Am.Chem. Soc., 97, 5577(1975).

SUGIURA, Y.; HIRAYAMA, Y.: Inorg. Chem., 1.5, 679 (1976): J.Am. Chem. Soc., 99, 1581 (1976).

SUNDBERG,R.J.; MARTIN,R.B.: Chem.Rev., 74, 471 (1974)

VANGARD, T.:"Magnetic Resonance in Biological Systems",Ehrenberg,

A.: Malmstrom, B.G.; Vangard,T.(eds.) Oxford,London : Pergamon (1967).

VANNGARD,T.:"Copper Proteins". In: Biological Applications of Electron Spin Resonance, Chap.9. Swartz, H.M.; Balton, J.R: ; Borg, D.C. (eds) N.Y., London: Wiley-Interscience (1972) .

WITWICKI,J .; ZAKYEWSKI,K.: Eur.J.Biochem., 10, 284(1969) 